\title{
GÊNESE E EVOLUÇÃO DOS GRANITÓIDES METALUMINOSOS DE AFINIDADE ALCALINA DA PORÇÃO OESTE DO ESCUDO SUL-RIOGRANDENSE: GEOQUÍMICA E ISÓTOPOS DE RB-SR E PB-PB
}

\author{
MARIA DO CARMO PINTO GASTAL* \& JEAN MICHEL LAFON**
}

\begin{abstract}
THE ORIGIN AND EVOLUTION OF THE METALUMINOUS AND ALKALINE GRANITES, FROM THE WESTERN PORTION OF THE SUL-RIOGRANDENSE SHIELD: GEOCHEMIST, AND Rb-Sr AND Pb-Pb ISOTOPES The mctaluminous granites with alkaline affinity or tendency occur in lhe west and east portions of the Sul-riograndense Shield. They are separated in three groups. Although ali three might be related to A-type granites, in the wide sense of the term, theirgeochemical and isotopic features reflect differences in the sources or in the generation processes. These granites, in the east, have highly fractionated calc-alkaline nature, with alkaline tendency and are derived from sources enriched in $\mathrm{K}_{2} \mathrm{O}, \mathrm{Rb}, \mathrm{U}$ and Th and depleted in $\mathrm{Nb}$. In the west, they show more prominent alkaline affinity and are grouped in the Saibro Intrusive Suite. This suite hás two metaluminous granite types and the compositional variations among them is strongly constrained by intensity and diversity in the crusta! contribution. The strongly alkaline ones have mantle signature and are related to the end of an early magmatic event $(580-610 \mathrm{Ma})$, with dominant shoshonitic affinity. The metaluminous sensu strictu terms are associated to a later event $(540-560 \mathrm{Ma})$ with more prominent participation of crustal sources. The main differences between the two types, that allow related respectively to A-1 and A-2 granites, include variations in the values of $\mathrm{CaO} / \mathrm{alkalis}, \mathrm{Ba} / \mathrm{Sr}$, $\mathrm{Y} / \mathrm{Nb}$ and $\mathrm{Zr} / \mathrm{Nb}$ ratios; in the content and geochemical behavior of $\mathrm{Zr}$, and in the composition of mafic phases. The compositional characteristics indicating source types are also common to the composition of the rest of the granites later in the Brasiliano Cycle, in the west portion, independem of their geochemical signature (high $\mathrm{K}$ calc-alkaline, shoshonitic and alkaline). This allow to establish two regional domains: I) north-northeast portion (Caçapava do Sul - São Sepé) where the granitoids have strong crustal influence, as shown by the high negative values of EMI, moderate to high $\left({ }^{8} \mathrm{Sr}{ }^{86} \mathrm{Sr}\right) \mathrm{i}$ and, in the alkaline ones, lower initial Pb isotopic ratios; and 2) center-south portion (Lavras do Sul), where compositions with important mantle signature predominate. These granites show lower values of $\left({ }^{87} \mathrm{Sr}{ }^{86} \mathrm{Sr}\right)$ and $\varepsilon_{N} d$ similar to the primitive mantle. Although the two granite groups are distributed in distinct regional domains, the evolution in the magmatic events, characterized by the transition in the geochemical affinity (shoshonitic-alkaline) and by the increasing crustal contribution, also occur in time, as illustrated in the region of the granites Jaguari-Lavras.
\end{abstract}

Keywords: granites; Neoproterozoic; diversity in A-type granites; Saibro Intrusive Suite; $\mathrm{Nd}-\mathrm{Sr}-\mathrm{Pb}$ isotopic geochemist; $\mathrm{Pb}-\mathrm{Pb}$ and $\mathrm{Rb}-\mathrm{Sr}$ geochronology

RESUMO Os granitos metaluminosos de afinidade, ou de tendência alcalina, das porções leste c oeste do Escudo Sul-riograndense foram separados em três grupos. Embora todos possam ser englobados como tipo A, no sentido mais amplo do termo, suas características geoquímicas e isotópicas traduzem fontes ou processos geradores distintos. No leste, ocorrem os tipos cálcico-alcalinos altamente fracionados, de tendência alcalina, derivados de fontes ricas em $\mathrm{K}_{2} \mathrm{O}, \mathrm{Rb}, \mathrm{U}$ e Th e pobres em Nb. No oeste, os granitos da Suite Intrusiva Saibro exibem afinidade alcalina mais marcante. São subdivididos em dois grupos e sua variação composicional é controloda pela intensidade e diversidade da contribuição crustal. Os tipos fortemente alcalinos são derivados de parentais mantélicos e estão relacionados ao final de evento magmático precoce $(580-610 \mathrm{Ma})$, de natureza dominantemente shoshonítica. Os termos metaluminosos s.s desta suite, no entanto, estão associados a evento mais tardio (540-560 Ma), e sua gênese envolve maior participação de fontes crustais. As principais diferenças entre os dois tipos, que permitem correlacioná-los respectivamente aos granitos A-1 e A-2, compreendem as variações das razões cálcio/álcalis, Ba/Sr, $\mathrm{Y} / \mathrm{Nb}$ e $\mathrm{Zr} / \mathrm{Nb}$; o conteúdo e comportamento geoquímico do $\mathrm{Zr}$ e a composicão das fases máficas. As características composicionais indicativas da fonte são também comuns à composição dos demais granitóides tardios do Ciclo Brasiliano no setor oeste, independente de sua afinidade geoquímica (cálcico-alcalina alto K, shoshonítica e alcalina). Isto permite estabelecer a existência de dois domínios regionais: 1) porção norte-nordeste (Caçapava do Sul - São Sepé), onde os granitóides possuem influência crustal, como evidenciado pêlos altos valores negativos de ENJ, moderados a baixos de $\left.{ }^{87} \mathrm{Sr}{ }^{80} \mathrm{Sr}\right)$ e, no caso dos alcalinos, baixas razões isotópicas iniciais do $\mathrm{Pb}$; e 2) porção centro-sul (Lavras do Sul), onde predominam as composições com derivação mantélica mais importante, caracterizadas pêlos baixos valores das razões $\left.{ }^{87} \mathrm{Sr}^{\gamma 86} \mathrm{Sr}\right)$, e de $\varepsilon_{\mathrm{Nd}}$, próximos aos do manto primitivo. Embora estes dois tipos distribuam-se em domínios distintos, a evolução dos eventos magmáticos, caracterizada pela transição na afinidade geoquímica (shoshonítica -alcalina) e pelo crescimento da contribuição crustal, ocorre também no tempo, como ilustrado na região dos granitos Jaguari-Lavras.

Palavras-chaves: granitos; Neoproterozóico; diversidade de granitos tipo A; Suite Intrusiva Saibro; geoquímica isotópica $\mathrm{Nd}-\mathrm{Sr}-\mathrm{Pb}$; geocronologia $\mathrm{Pb}-\mathrm{Pb}$ e $\mathrm{Rb}-\mathrm{Sr}$

INTRODUÇÃO Os eventos finais do Ciclo Brasiliano no Escudo Sul-riograndense estão representados por intenso magmatismo granítico. No leste, predominam os granitóides cálcico-alcalinos evoluídos, com termos alcalinos subordinados, que formam o arcabouço do Batólito Pelotas. No oeste, as associações magmáticas, cronocorrelatas às do leste, exibem maior diversidade composicional, sendo representadas por granitos cálcico-alcalinos alto $\mathrm{K}$ e por rochas efusivas e plutônicas, de afinidade shoshonítica e alcalina. Essas últimas incluem sequências vulcânicas félsicas, pertencentes à Formação Acampamento Velho; e inúmeros corpos graníticos metaluminosos, termos peralcalinos, quartzo sienitos e rochas intermediárias a básicas, todos agrupados na
Suite Intrusiva Saibro - SIS (Nardi \& Bonin 1991), como proposto por Gastai et al. (1992).

Este trabalho sintetiza as feições petrográfícas, geoquímicas e isotópicas $(\mathrm{Rb}-\mathrm{Sr}$ e $\mathrm{Pb}-\mathrm{Pb})$ dos granitos metaluminosos de afinidade alcalina da SIS, objetivando a discussão de sua gênese. As comparações com tipes shoshoníticos e cálcicoalcalinos alto $\mathrm{K}$ destinam-se a avaliar a polaridade e evolução do magmatismo no final do Ciclo Brasiliano.

GEOLOGIA DA PORÇÃO OESTE DO ESCUDO SUL-RIOGRANDENSE Os modelos geotectônicos propostos para o Escudo Sul-riograndense incluem a existência de duas faixas móveis brasilianas, relacionadas ao mesmo

* Centro de Estudos em Petrologia e Geoquímica - CPGq, Instituto de Geociências, UFRGS; Caixa Postal 15001. CEP 91 501. 970, Porto Alegre, RS, Brasil; Fax 051-3391811.

** Laboratório de Geologia Isotópica, Centro de Geociências, UFPA. Caixa Postal 1611, CEP 66075.900, Belém, PA, Brasil. 
evento orogênico, ou a episódios tectono-termais distintos. A expressiva granitogênese da porção leste formou-se durante regimes tectônicos distintos, relacionados ao evento colisional Dom Feliciano ( $600 \mathrm{Ma})$ (Chemale et al. 1995). A porção oeste é segmentada, transversalmente, nos blocos Taquarcmbó e São Gabriel (Fig. 1). Os terrenos de alto grau paleoproterozóicos estão representados pelo Complexo Granulítico Santa Maria Chico, e os de baixo a médio grau neoproterozóicos foram formados durante o evento São Gabriel (700 Ma), com características de arco magmático. Estes últimos são compostos por três associações de rochas distintas: Complexo Cambai; unidades máfico-ultramáficas e sequências vulcanosedimentares, ambas agrupadas como Supcrgrupo Vacacaí (Chemale et al. 1995). Os reflexos do Evento Dom Feliciano na porção oeste estão representados pelo magmatismo tardio, concomitante à deposição de molassas da Bacia de Camaquã (Fig. 1). Essa possui, na base, características de bacia de retroarco assimétrica e evoluiu para bacias parcialmente conectadas do tipo strike-slip (Paim et al. 1995). Assim, as questões básicas da evolução do magmatismo tardi- a pósorogênico da porção oeste referem-se ao seu posicionamento durante o soerguimento progressivo desta região, sucedendo à justaposição dos dois terrenos mais antigos.

Granitóides Segundo o enfoque monocíclico, o magmatismo tardio (cálcico-alcalino alto $\mathrm{K}$, shoshonítico e alcalino) estaria relacionado ao mesmo evento tcctono-tcrmal iniciado em 750-700 Ma. Representaria, assim, episódios sucessivos (650-600Ma e 550-500Ma), atestando a estabilização da região com o tempo, similar à evolução de margens continentais maturas (Soliani 1986, Nardi et al. 1992). Os modelos recentes, no entanto, admitem a evolução do magmatismo granítico e intermediário, nesta porção, relacionada a episódios distintos. Chemale et al (1995), com base em dados isotópicos, relacionam o magmatismo tardio ao evento Dom Feliciano, interpretando-o como reflexo desse episódio colisional no antepaís. Grande parte dos granitóides deformados e de composição cálcico-alcalina médio a baixo $\mathrm{K}$, referidos genericamente como sin-orogênicos ou precoces (Fernandes et al. 1992), são interpretados como remanescentes da infraestrutura de um arco magmático e correlacionados ao Complexo Cambai.

Os dados isotópicos e as principais feições composicionais distintivas dos granitóides tardios no Ciclo Brasiliano da porção oeste do Escudo são sintetizados na Tabela 1. As idades, situadas no intervalo entre 540-560Ma e 600-61 OMa, apontam a contemporaneidade entre os episódios magmáticos com diferentes afinidades geoquímicas. As composições cálcico-alcalinas alto $\mathrm{K}$, representadas pelo Complexo Granítico Caçapava do Sul (CGCS) e Suíte Intrusiva Santo Afonso (SIAF), apresentam muitas analogias composicionais (Fig. 2).

Magmatismo intermediário a ácido As ocorrências de rochas vulcânicas intermediárias (Formação Hilário) são fortemente controladas pelas estruturas tectônicas de direção NE-SW e, junto aos granitóides cálcico-alcalinos alto $\mathrm{K}$, concentram-se na parte leste-sudeste da região (Fig. 1). A norte, próximo às cidades de São Sepé e Caçapava do Sul, essas vulcânicas exibem afinidade cálcico-alcalina alto $\mathrm{K}$ e evoluem, em direção sul (Lavras do Sul), para shoshonítica (Wildner \& Lima 1992). Na região de Lavras do Sul, a associação shoshonítica inclui espesso pacote vulcanogênico, lamprófiros espessartíticos e grande variedade de intrusivas intermediárias a ácidas (Lima \& Nardi 1997).

As vulcânicas ácidas (Formação Acampamento Velho) ocorrem em platôs relativamente extensos e, junto aos granitóides da Suíte Intrusiva Saibro, distribuem-se na parte oeste-noroeste da região oeste (Fig. 1). A zonalidade no magmatismo, com a passagem das composições cálcico-alcalinas ( \pm shoshoníticas) para alcalinas (super)saturadas, no sentido W-NW, é também evidenciada entre estas últimas. Neste sentido, ocorre a transição dos tipos metaluminosos para pcralcalinos, que predominam nos platôs vulcânicos (Roisenberg et al 1983, Sommer 1994). As sequências vulcanogênicas situadas mais a leste, próximo à Caçapava do Sul (Wildner et al 1994), são metaluminosas e seu conteúdo de elementos traço é equiparável ao de granitos menos marcadamente alcalinos da SIS, como o Complexo Granítico Ramada (Figs. 2E, 3C e 3H). Os Diques Armeiras de composição intermediária a básica que ocorrem a oeste do Granito Jaguari, são também correlacionados à esta suíte (Figs. 1 e 5). Estes orientam-se segundo NE-SW e incluem microdioritos de afinidade alcalina (Gastai et al \992), com micromonzonitos subordinados e similares aos termos shoshoníticos.

Além das características distintivas mostradas na Tabela 1 , as composições shoshoníticas destacam-se pêlos trenas de crescimento regular do $\mathrm{K} 2 \mathrm{O}$ com a diferenciação, similar à evolução dos tipos cálcico-alcalinos (Fig. 2D); pelas razoes $\mathrm{Rb} / \mathrm{Zr}$ mais elevadas (Fig. 2F); e por se deslocarem das composições de granitos intraplaca, devido aos menores teores de Y (Figs. 3B e D). O Maciço Granítico Santo António, no entanto, exibe características geoquímicas mais próximas aos granitos alcalinos, como evidenciado nas figuras $2 \mathrm{~F}, 3 \mathrm{~B}$ e3C.

Granitóides metaluminosos e alcalinos A comparação de diferentes granitos metaluminosos de afinidade ou de tendência alcalina, situados nas porções leste e oeste do Escudo Sul-riograndense, permitiu separá-los em conjuntos diversos, traduzindo variações composicionais regionais, como discutido por Gastai et al. (1995a e b). Manteve-se a distinção entre os granitos de afinidade alcalina, para os termos caracteristicamente do tipo A (Eby 1990) e de tendência alcalina, para aqueles cálcico-alcalinos altamente fracionados, similares aos do tipo A (Sylvester 1989). Esta separação, embora informal, traduz as diferenças composicionais e genéticas entre os dois conjuntos. Os critérios de alcalinidade utilizados incluem variações entre elementos maiores - $\mathrm{CaO}, \mathrm{Al}_{2} \mathrm{O}_{3}$ e $\mathrm{Na}_{2} \mathrm{O}+\mathrm{K}_{2} \mathrm{O}$, elementos traço incompatíveis - Nb, Y, Ga e Zr, e os padrões de ETR. Os granitos do leste destacam-se, em relação aos do oeste, pêlos valores mais elevados de $\mathrm{K}_{2} \mathrm{O}$ e $\mathrm{Rb}$, baixos de $\mathrm{Nb}$, e consequente aumento nas razões $\mathrm{Rb} / \mathrm{Zr}$ e $\mathrm{Y} / \mathrm{Nb}$ e decréscimo na razão $\mathrm{Zr} / \mathrm{Nb}$ (Figs. 2D, 2F, 3D e 3H). Os granitos metaluminosos da Suíte Granítica Dom Feliciano (SGDF - Fig. 1), assemelhamse aos tipos cálcico-alcalinos alto K. Seus termos mais evoluídos (granitos tipo Serra do Herval) exibem teores mais altos de $\mathrm{Y}, \mathrm{Ga}$ e $\mathrm{Nb}$, o que lhes confere composição mais próxima das alcalinas (Figs. 3B, D e H). No entanto, diferem dos tipos metaluminosos da Suíte Intrusiva Saibro em função das maiores razões $\mathrm{Y} / \mathrm{Nb}$ e $\mathrm{Ce} / \mathrm{Nb}$, indicativas de derivação a partir de fontes com maior envolvimento da subducção (Fig. 3F).

Os granitóides da Suíte Intrusiva Saibro, com exceção do Complexo Granítico Ramada, enquadram-se no campo dos tipos intraplaca de Pearce et al. (1984) (Figs. 3A e C). Os granitos metaluminosos e alcalinos são os termos dominantes nesta suíte (Nardi 1991) e foram subdivididos nos grupos metaluminoso fortemente alcalino e metaluminoso sensu strictu, os quais exibem trenas evolutivos distintos e, muitas vezes, sub-paralelos (Figs. 2 e 3 ). Os tipos metaluminosos fortemente alcalinos, representados pelas fácies alcalinas do Complexo Intrusivo Lavras do Sul e Quartzo Monzonito Tuna, possuem anfibólios cálcicos -edenita e ferro-edenita (Fig. 4), e exibem trenas geoquímicos similares aos de associações peralcalinas (Fig. $2 \mathrm{~A}, 2 \mathrm{E}$ e $3 \mathrm{H}$ ). Os dois exemplos deste tipo diferem entre si pelo forte crescimento no conteúdo de ETRL no Quartzo Monzonito Tuna, traduzindo a presença significativa de alanita (Gastai et al 1992), e pela composição dos anfibólios (Fig. 4). Nas fácies alcalinas do Complexo 

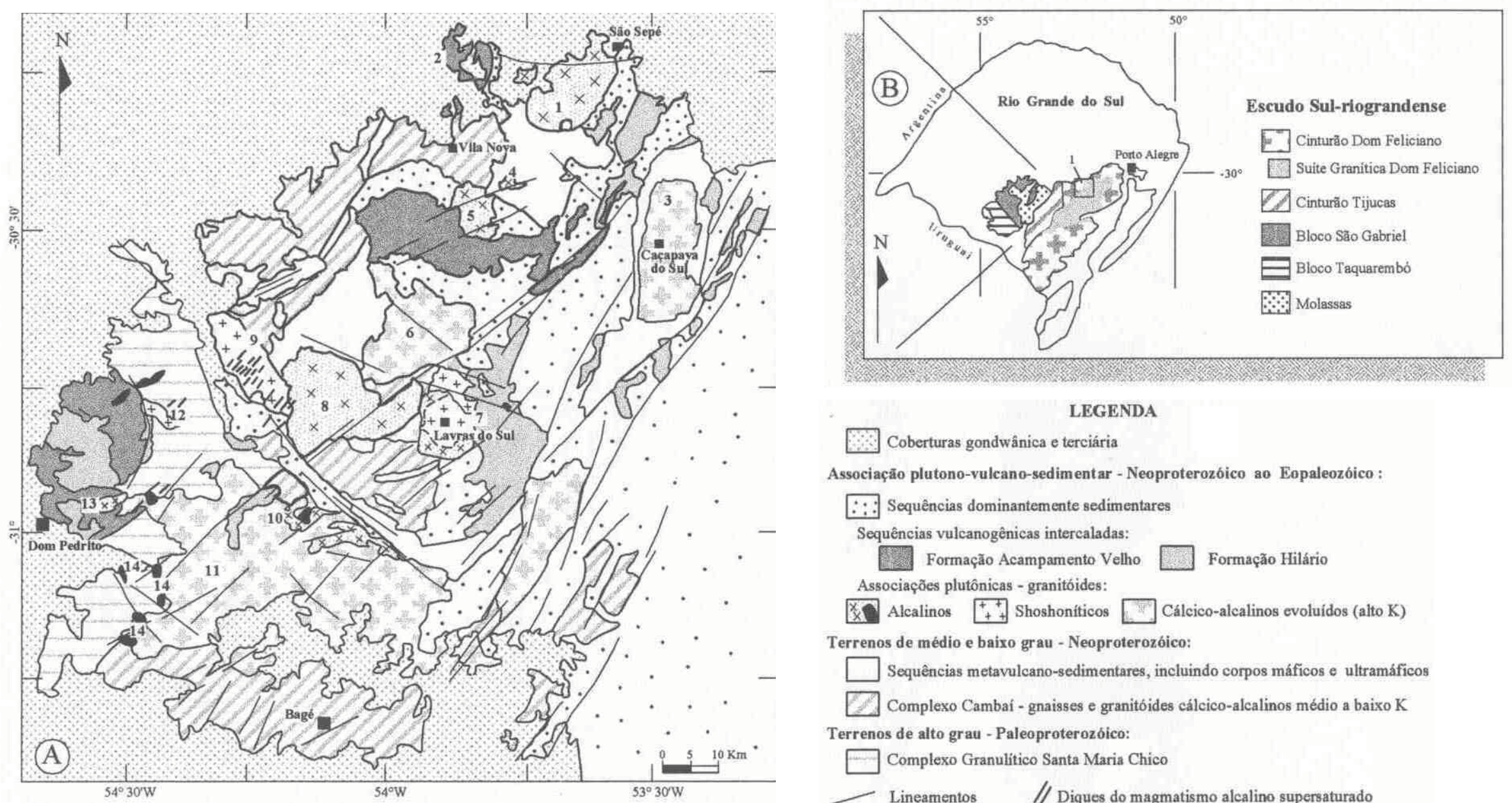

Coberturas gondwânica e terciária

Associação plutono-vulcano-sedimentar - Neoproterozóico ao Eopaleozóico :

$\therefore$ Sequências dominantemente sedimentares

Sequências vulcanogênicas intercaladas:

Formação Acampamento Velho $\square$ Formação Hilário

Associą̧̃̃es plutônicas - granitóides:

Alcalinos ${ }_{+}^{+}+$Shoshoniticos Cálcico-alcalinos evoluídos (alto $\mathrm{K}$ )

Terrenos de médio e baixo grau - Neoproterozóico:

$\square$ Sequências metavulcano-sedimentares, incluindo corpos máficos e ultramáficos

Complexo Cambai - gnaisses e granitóides cálcico-alcalinos médio a baixo $\mathrm{K}$

Terrenos de alto grau - Paleoproterozóico:

$\square$ Complexo Granulitico Santa Maria Chico

Lineamentos // Diques do magmatismo alcalino supersaturado

Figura l - Mapa geológico da porção oeste do Escudo Sul-riograndense - A; granitóides (e vulcânicas): (1) Complexo Granitico São Sepé (CGSS); (2) vulcânicas alcalinas do Cerro Tupancy; (3) Complexo Granítico Caçapava do Sul (CGCS); (4) Granito Cerro da Cria (GCC); (5) Complexo Granítico Ramada (CGR); (6) Granodiorito Santa Luzia e Monzogranito São Manoel; (7) Complexo Intrusivo Lavras do Sul (CILS); (8) Granito Jaguari (GJ); (9) Monzogranito Santa Rita; (10) Granito Saibro (GS) e

Quartzo Monzonito Tuna (QMT); (11) Suite Intrusiva Santo Afonso (SIAF); (12) Maciço Granítico Santo António (MGSA); (13) Complexo Anelar Leões (CAL); (14)

granitos peralcalinos de Dom Pedrito. (B) -Principais unidades geotectônicas do escudo, onde campo (1) salienta a localização dos granitóides da porção leste referidos no texto.

Figure l- Geologic imip ofthe west portion ofthe Sul-riograndense Shield - A; granitoids (and volcanics): (1) São Sepé Granitic Complex; (2) Alkaline volcanics ofthe Cerro Tupancy; (3) Caçapava do Sul Grani tic Complex; (4) Cerro da Cria Granite; (5) Ramada Granitic Complex; (6) Santa Luzia Granodiorite and São Manoel Monz.ogranite; (7) Lavras do Sul Intrusive Complex; (8) Jaguari Granite; (9) Santa Rita

Monzogranite; (10) Saibro Granite e Tuna Quartz-monz.onite; (11) Santo Afonso Intrusive Suite; (12) Santo António Granitic Maxsive; (13) Leões Ring Complex; (14) peralkaline granites ofthe Dom Pedrito's área (B) -Main geotectonic.s units ofthe sllield, where field (1) lighhlights the localization ofthe referred granitoids from the east ponion. 


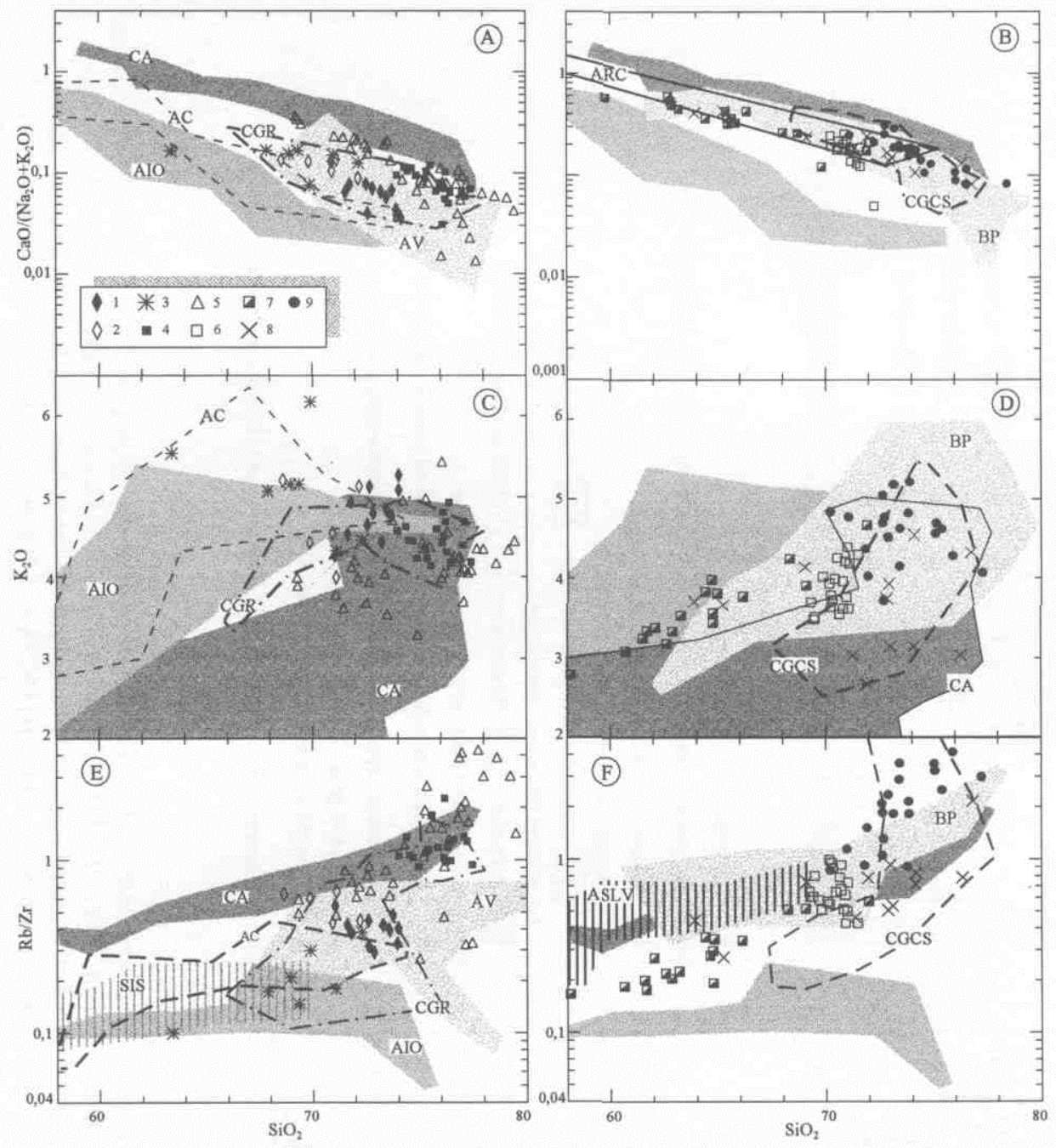

2 - Diagramas da razão cálcio-alcalina versus $\mathrm{SiO}_{2}$ (A e B); $K_{2} \mathrm{O}$ versus $\mathrm{SiO}_{2}$ (C e D); e $\mathrm{Rb} / \mathrm{Zr}$ versas $\mathrm{SiO}_{2}(\boldsymbol{E}$ e $\boldsymbol{F})$ de granitóides metaluminosos da SIS (A, C e E), comparados a exemplos da bibliografia, e a granitóides cálcico-alcalinos e shoshoníticos do Escudo Sul-riograndense (B, D e F). Associações cálcico-alcalinas - CA. Batólito Sierra Nevada (Ague \& Brimhall 1988) e plutons japoneses (Czamanske et al. 1981); Associações alcalinas (super)saturadas de ilhas oceânicas - AIO: Ascencion (Harris 1983) e Atol de Mururoa (Caroff et al. 1993); e de ambientes continentais -AC: Kane Springs Wash Caldera (Novak \& Mahood 1986) e Kenya Rift (Baker 1987). Em B, ARC - campo das associações de arco magmático (Brown 1982) Granitóides alcalinos da Suíte Intrusiva Saibro (SIS): metaluminosos fortemente alcalinos: 1 - pertiía granitos e 2 -sienogranitos do Complexo Intrusivo Lavras do Sul (C1LS); 3 - Quartzo Monzonito Tuna; e metaluminosos s.s.: 4 - Granito Jaguari e 5 - Complexo Granítico São Sepé. Outros granitóides: shoshoníticos: 6 - monzogranitos do núcleo do CILS (Nardi 1984) e 7 - Maciço Granítico Santo António (Barros \& Nardi 1994); cálcico-alcalinos alto K: 8 - Suíte Intrusiva Santo Afonso (Gastai et al. 1992); e cálcico-alcalinos altamente fracionados, de tendência alcalina: 9 - Suíte Granítica Dom Feliciano - SGDF (região de Encruzilhada do Sul; UFRGS 1992). São mostrados, ainda, os campos dos seguintes corpos graníticos: CGR - Complexo Granítico Ramada (Naime \& Nardi 1991); CGCS - Complexo Granitico Caçapava do Sul (Nardi \& Bitencourt 1989), BP -granitóides cálcico-alcalinos do leste (tardi-a pós-transcorrencia) (Philipp 1991; Gomes et al. 1991; Frantz \& Nardi 1992); e $\boldsymbol{A} \boldsymbol{V}$ - vulcânicas da Formação Acampamento Velho (FL Passo Salsinho; Wildner et al. 1994). Em E e $\boldsymbol{F}$, campos hachurados para os termos intermediários a básicos, respectivamente, das associações alcalina super(saturada) - SIS e shoshonítica - ASLV (Associação Shoshonítica de Lavras do Sul; Lima \& Nardi 1992), segundo Gastai et al. (1992).

Figure $2-\mathrm{SiO}_{2}$ versus calc-alkaline ratio (A and $\left.\mathbf{B}\right), \mathrm{K}_{2} \mathrm{O}$ versus $\mathrm{SiO}_{2}(\mathbf{C}$ and $\mathbf{D})$ ), and $\mathrm{Rb} / \mathrm{Zr}$ versus $\mathrm{SiO}_{2}(\mathbf{E}$ and $\mathbf{F})$ diagrams for SIS metalummous gramtoids (A C and E) compared to bibliographic examples, and to calc-alkaline and shoshonitic granitoids from the Sul-riograndense Shield (B, D and F). Calc-alkalne associations - CA: Sierra Nevada Batholith (Ague \& Brimhall 1988), and Japanese plutons (Czamanske et al. 1981 ); (over)saturatcd alkalinc associations frorn ocean islands -AIO: Ascension (Harris 1983), and Mururoa Atoll (Caroff et al. 1993); and from continental settings - AC: Kane Springs Wash Caldera (Novak 6 Mahood 1986), and Kenya Rift (Baker 1987). Field ARC, in B, for arc-magmatic associations (Brown 1982). Alkalinc granitoids of the Saibro Intrusive Suite (SIS)' strongly alkaline metaluminous: 1 - pertithe granitcs and 2- syenogranites of the Lavras do Sul Intrusive Complex (CILS); 3 - Tuna Quartz-monzomte; and metaluminous s.s.: 4 - Jaguari Granite and 5 - São Sepé Granitic Complex. Others granitoids: shoshonitic: 6 - monzogranites of the CILS (Nardi 1984) and 7 - Santo António Granitic Massive (Barros \& Nardi 1984); high K calc-alkaline: 8 - Santo Afonso Intrusive Suite ( Gastai et al. 1992); and highly evolved calc-alkaline with alkaline tendency: 9 - Dom Feliciano Granitic Suite - SGDF (Encruzilhada do Sul's área, UFRGS 1992). It is also shown the fields for the following grànitic bodies: CGR - Ramada Granitic Complex (Naime \& Nardi 1991 ); CGCS - Caçapava do Sul Granitic Complex (Nardi \& Bitencourt 1989); BP - calc-alkaline granitoids from the east sector (tardi to post-transcurrence) (Philipp 1991; Gomes et al. 1991; Frantz \& Nardi 1992); and AV - volcamcs of the Acampamento Velho Formation (Passo Salsinho's área, Wildner et al. 1994). In $\mathbf{E}$ and $\mathbf{F}$, hachures for the field of the intermediate to basic terms respectively of alkaline (over)saturated association - SIS, and of shohsonitic ones -ASLV (Lima \& Nardi 1992), according to Gastai et al. (1992). 

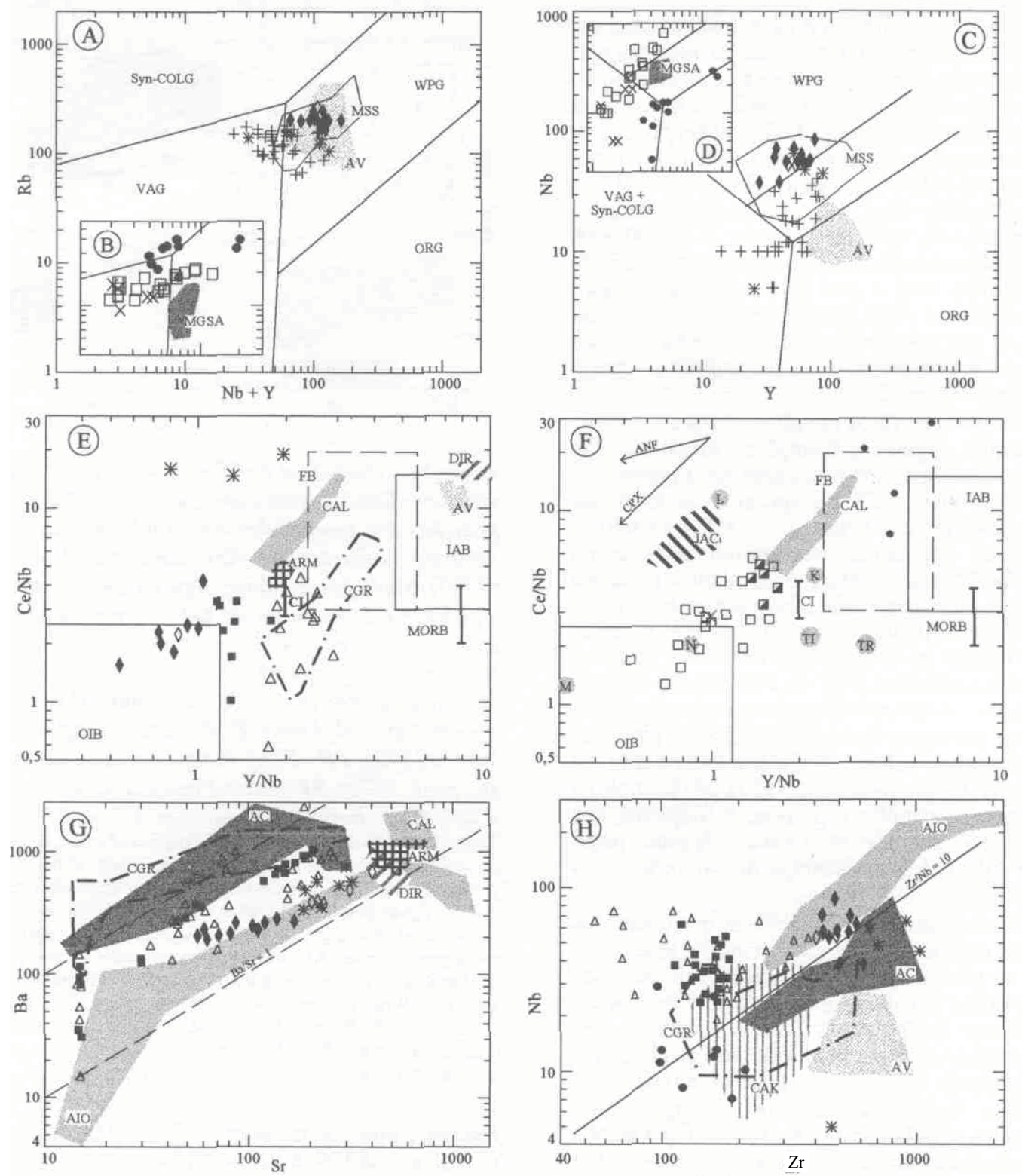

Figura 3 - Comportamento de elementos traço de granitóides metalwninosos da SIS, comparados a algumas associações clássicas. Símbolos e referências, vide figura 2. (A $\boldsymbol{e} \boldsymbol{B}) \mathrm{Rb}$ versus $(Y+N b)$ e $(\boldsymbol{C} \boldsymbol{e} \boldsymbol{D}) \mathrm{Nb}$ versus $Y$, com a classificação dos granitóides segundo Pearce et al. (1984). Em A e C, MSS - campo dos granitos metaliiminosos s.s. da SIS (GJ e CGSS); e cruzes - CGR. (E e F)- Ce/Nb versus Y/Nb; campos segundo Eby (1990): $\boldsymbol{C I}$ - média da crosta inferior (Taylor \& McLennan 1985); FB - granitos orogênicos, e principais tipos de basaltos: OIB; MORB - limite N-MORB; e IAB - basaltos de arcos de ilhas relativamente ricos em $\mathrm{Nb}$ e Ta. Composição de basaltos alcalinos e toleiticos exibidos em (F): K-Kane Springs Wash Caldera (Novak \& Mahood 1986); M - Atol de Mururoa (Caroff et al. 1993); N - Naivash, TI -toleito intraplaca e TR - toleito de retroarco (Wilson J989); e $\boldsymbol{L}$ - média de lamprófiros cálcico-alcalinos (Rock 1987). Setas ilustram sentido do f racionamento de clinopiroxênio e anfibólio, em líquidos riolíticos (Eby 1990).(G) Ba-Sr; e (H) $\mathrm{Nb}-\mathrm{Zr}$, onde CAK - campo dos riolitos de associações cálcico-alcalinas alto K (Ewart 1982); e AC e AIO - associações alcalinas, como na figura 2. Campos das rochas intermediárias a básicas relacionadas aos granitóides da SIS: CAL - monzodioritos e quartzo monzodioritos do Complexo Anelar Leões (S/02.' 52 a 57\%); ARM - Diques Armeiras (microdioritos) ( $\mathrm{SiO}_{2}: 51$ a 54\%); DIR - dioritos do CGR (SiO $: 50$ a 57 \%); e JA C- Monzodiorito Arroio do Jacques

(CILS; Tabela 2).

Figure 3 - Trace-element diagrams for the metaluminous granitoids of the SIS compared with some classic associations. Symbols and references as $\mathrm{m}$ figure 2. (A and $\mathbf{B}) \mathrm{Rb}$ versus $(\mathrm{Y}+\mathrm{Nb}$ ) and $(\mathbf{C}$ and $\mathbf{D}) \mathrm{Nb}$ versus $\mathrm{Y}$, with the granitic classification after Pearce et al. (1984). In A and C, MSS - field for the SIS metaluminous s s granites (GJ and CGSS); and crosses for CGR.(E and F) - Ce/Nb versus $\mathrm{Y} / \mathrm{Nb}$, with fields according to Eby (1990): $\mathrm{Cl}$ - average lowcr crust (Taylor \& McLennan 1985)- FB - orogenic granites; and for the main basaltic typcs: OIB, MORB - limit of N-MORB, and IAB - relatively Nb and Ta ennched Island Are Basalts Composition of alkaline and tholeiitic basalts shown in (F): K - Kane Springs Wash Caldera (Novak \& Mahood 1986); M - Mururoa Atoll (Caroff et al. 1993); N - Naivash, TI - intra-plate tholeiite e TR -back-arc tholeiite (Wilson 1989); and L - average calc-alkaline lamprophyres (Rock 1987). Arrows show the fractionation trend for clinopyroxene and amphibole for rhyolitic magmas (Eby 1990).

(G) Ba-Sr; and (H) Nb-Zr, where CAK - field for rhyolites with high K calc-alkaline affinity (Ewart 1982); and AC and AIO - alkaline associations, as in figure 2 Fields for intermediate to basic rocks related to SIS granitoids: CAL -monzodiorites and quartz-monzodiorites of the Leões Ring Complex (SiO 2 : 52 to $57 \%$ ); ARM - Armeiras Dikes (microdiorites) $\left(\mathrm{SiO}_{2}: 51\right.$ to 54\%); DIR - diorites of the Ramada Granitic Complex (SiOa: 50 to 57 \%); and JAC -Arroio do Jacques Monzodiorite (CILS; Table 2). 
Intrusivo Lavras do Sul, o anfibólio é menos aluminoso, e o crescimento da razão $\mathrm{Fe} /(\mathrm{Fe}+\mathrm{Mg})$ no sentido da diferenciação evidencia a evolução em direção às composições sódico-cálcicas. No Quartzo MonzonitoTuna, os anfibólios são mais aluminosos, e os contrastes nas razões $\mathrm{Fe} /(\mathrm{Fe}+\mathrm{Mg})$ podem ser atribuídos a diferentes graus de hibridismo. Esta diversidade na composição dos anfibólios é análoga à observada no Pliny Range Intrusive Complex (Fig. 4), cuja história evolutiva envolve hibridismo significativo (Czamanske et al. 1977). A individualização do Quartzo Monzonito Tuna relativo à Suíte Intrusiva Santo Afonso, com a qual está intimamente associado (Fig. 1), justifica-se pelas evidências de campo e texturais, sugestivas de sua intrusão nas fácies desta suíte e pelo contraste composicional entre os dois, incompatível com o fracionamento mineral (Figs. 2 e 3 ).

As feições distintivas dos tipos metaluminosos s.s., representados pelo Granito Jaguari e Complexo Granítico São Sepé, resumidas na Tabela 1, são mostradas nas Figuras 2A, 3E, 3G e 3H. Dentre eles, o CGSS aproxima-se mais das composições cálcico-alcalinas (Figs. 2A e C). Contudo, a bifurcação dos trenas nas fácies mais diferenciadas, como exibido pelo $\mathrm{Zr}$ (Fig. 2E e $3 \mathrm{H}$ ), evidencia também a presença de composições mais alcalinas, o que talvez seja indicativo de sua natureza policíclica. As diferenças entre os dois granitos estão também refletidas na composição das fases máficas, como ilustrado pêlos anfibólios (Fig. 4). No Granito Jaguari, o anfibólio é escasso, relativamente tardio na cristalização c pertence a um grupo particular típico de associações alcalinas metaluminosas, com altos valores de $\mathrm{FeOt}$ e $\mathrm{Fe} /(\mathrm{Fe}+\mathrm{Mg})$, e baixo conteúdo de Al (Czamanske et al. 1977). No Complexo Granítico São Sepé, o anfibólio é precoce e frequente nos monzogranitos. Difere daquele do Granito Jaguari pelas menores razões $\mathrm{Fe} /(\mathrm{Fe}+\mathrm{Mg})$, indicativas de diferenças nas condições de cristalização.

Os granitos Saibro e Cerro da Cria diferem dos exemplos típicos dos granitos metaluminosos S.S. por serem mais diferenciados, o que se traduz nos baixos percentuais de fases máficas (biotita/clorita) e valores extremamente baixos de elementos compatíveis. O Complexo Granítico Ramada representa um tipo particular de composição mctaluminosa e alcalina (Naime \& Nardi 1991). Suas fácies graníticas assemelham-se aos tipos fortemente alcalinos, principalmente, devido ao baixo conteúdo de $\mathrm{CaO}$ c das razões $\mathrm{CaO}$ /álcalis (Fig. 2A). Destacam-se dos demais granitos da Suítc Intrusiva Saibro pêlos teores mais baixos de $\mathrm{Nb}$ e altos de $\mathrm{Ba}$ (Figs. 3C, $\mathrm{E}, \mathrm{G}$ e H). A diversidade composicional c textural deste complexo pode ser atribuída ao hibridismo, como ilustrado pela composição dos anfibólios (Fig. 4), envolvendo líquidos básicos a intermediários também distintos (Figs. 3E e G). Os dioritos deste complexo diferem das demais rochas intermediárias a básicas associadas aos granitóides alcalinos (Armeiras e Complexo Anelar Leões), pelo menor conteúdo de $\mathrm{Sr}$ e $\mathrm{Ba}$ e pêlos valores mais elevados das razões $\mathrm{Y} / \mathrm{Nb}$ e $\mathrm{Ce} / \mathrm{Nb}$, os quais sugerem origem distinta.

\section{RESULTADOS ISOTÓPICOS Procedimentos} analíticos Os novos dados isotópicos $\mathrm{Rb}-\mathrm{Sr}(\mathrm{RT})$ e $\mathrm{Pb}-\mathrm{Pb}$ (monozircão e feldspato) foram obtidos por meio do espectrômetro de massa Isomass 54E, do Laboratório de Geologia Isotópica - LGI/CG/UFPA. As dosagens de $\mathrm{Rb}$ e $\mathrm{Sr}$ foram efetuadas por diluição isotópica, usando traçador misto enriquecido em ${ }^{87} \mathrm{Rb}$ e ${ }^{84} \mathrm{Sr}$. Os cálculos de regressão tiveram como base as teorias de York $(1966,1969)$, seguindo o algoritmo de Williamson (1968). No tratamento dos dados compilados da bibliografia, considerou-se urnerro analítico de $1 \%$ nas razões ${ }^{87} \mathrm{Rb} /{ }^{86} \mathrm{Sr}$ e de $0,1 \%$, nas ${ }^{87} \mathrm{Sr} /{ }^{86} \mathrm{Sr}$, quando os mesmos não são fornecidos.

Os cristais de zircão foram separados por métodos convencionais de concentração de minerais pesados a partir das

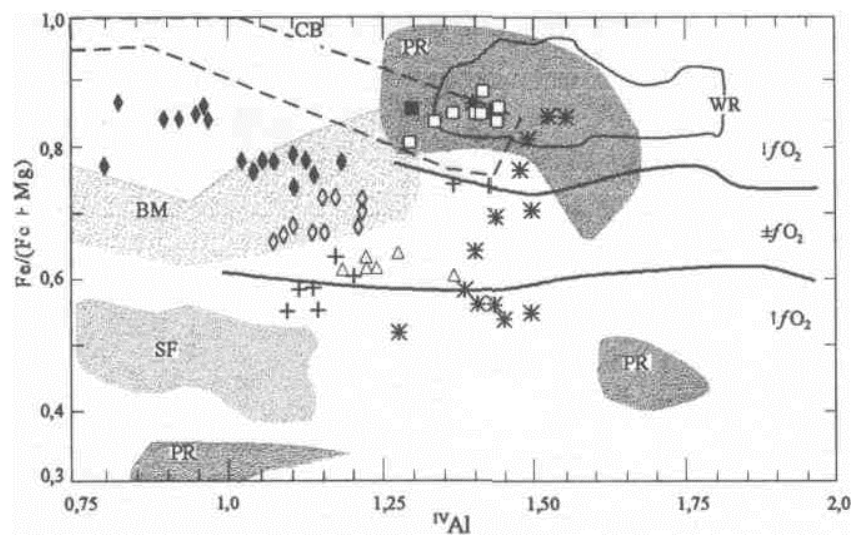

Figura 4 - Diagrama $\mathrm{Fe} /(\mathrm{Fe}+\mathrm{Mg})$ versus Al de anfibólios cálcicos (fórmula estrutural para 13 eCNK), exibindo composições dos granitóides metaluminosos da SIS. Subdivisão segundo variações de $\mathrm{fO}_{2}$, conforme Anderson \& Sinith (1995). Símbolos como nas figuras 2 e 3; e quadrado branco

- anfibólio de enclaves do GJ aparentemente em equilíbrio com a fácies sienogranítica. Associações alcalinas utilizadas para comparação: BM - Baie de Moutons Syenitic Complex (Lalonde \& Martin 1983); CB -Caurp Basíelica Ring Complex (Girei et al. 1980); $\boldsymbol{F}$-Finmark Complex (Czamanske \& Wones 1973); PR - Pliny Range Intrusive Complex (Czamanske et al. 1977); $\boldsymbol{S F}$-Saint François Mountain plutons e WR

- Wolf River Batholith (Anderson \& Smitli 1995). Figure $4-\mathrm{Fc} /(\mathrm{Fe}+\mathrm{Mg})$ versus ${ }^{\mathrm{IV}} \mathrm{A} 1$ diagram of calcic amphiboles (formulae on the basis of 13 cations), for compositions of the SIS metaluminous granitoids. Subdivision according to /Oi variations after Anderson \& Smith (1995). Symbols as in figures 2 and 3; and white square -amphibole of enclaves of the Jaguari Granite, apparently in equilibrium with the syenogranitic fácies. Alkaline associations used in the comparison: BM - Baie de Moutons Syenitic Complex (Lalonde \& Martin 1983); CB - Cauro Bastelica Ring Complex (Girct et al. 1980); F - Finmark Complex (Czamanske \& Wones 1973); PR - Pliny Range Intrusive Complex (Czamanske et al. 1977); SF - Saint François Mountain plutons and WR Wolf River Batholith (Anderson \& Smith 1995).

fraçõcs granulomólricas entre $0,17-0,062 \mathrm{~mm}$. A fração não magnética foi limpa por imersão em solução de $\mathrm{HNO}_{3} .7 \mathrm{~N}$ e água régia, a quente. As determinações isotópicas $\mathrm{Pb}-\mathrm{Pb}$ em monozircão foram efetuadas segundo procedimento modificado do método de Kobcr $(1986,1987)$, por meio da evaporação dircta do $\mathrm{Pb}$, como sintetizado por Gaudette et al. (1993). Para cada grão analisado, um bloco de resultados corresponde às medidas efetuadas no mesmo incremento de T. Este procedimento foi repetido a sucessivos incrementos de $\mathrm{T}$, até a remoção completa do $\mathrm{Pb}$. As idades aparentes ${ }^{207} \mathrm{~Pb} /{ }^{206} \mathrm{~Pb}$ de cada granito estudado foram obtidas pela média ponderada dos resultados de cada cristal analisado, após correção do $\mathrm{Pb}$ comum, e são interpretadas como valores mínimos da cristalização dos cristais de zircão e dos granitos (Macambira et al. 1994, Moura et al. 1996).

As amostras de feldspato, após cominuidas, foram lixiviadas com HF diluído (IN) para eliminar eventual $\mathrm{Pb}$ de contaminação ou introduzido após sua cristalização. Os procedimentos analíticos utilizados seguem o método de Manhes et al. (1978) e Manhes (1982), adaptado às condições do Laboratório de Geologia Isotópica da UFPA (Lafon et al. 1993). Em virtude dos cristais de feldspatos não conterem quantidades significativas de U e Th (Patterson \& Tatsumoto 1964), suas razões isotópicas do $\mathrm{Pb}$ são boas aproximações das razões iniciais dos magmas parentais e, assim, fornecem subsídios importantes à petrogênese (Doe \& Zartman 1979). Na compilação dos dados isotópicos, reuniu-se os resultados 


\section{Tabela $•$ Características composicionais e isotópicas dos granitos tardios do Ciclo Brasiliano, porção oeste do Escudo} Sul-riograndense.

Table l • Compositional and isotopic characteristics of lhe granites later in the Brasiliano Cycle, west portion of the Sul-riograndense Shield.

\begin{tabular}{|c|c|c|}
\hline Granito/Suíte & Características composicionais & Dados isotópicos \\
\hline $\begin{array}{l}\text { I. Cálcico-alcalinos alto K: } \\
\text { Complexo Granítico Caçapavu do Sul } \\
\text { (CGCS) } \\
\text { Suíte Intrusiva Santo Afonso (SIAF) }\end{array}$ & $\begin{array}{l}\text { Granilóides foliados c alclados cm diferentes imensidades pela tectônica } \\
\text { transcorrcntc (NE-SW c N-S). Biolila mon/ogranitos dominantes, com } \\
\text { granodioritos subordinados c leucomonzo- granitos levemente pcraluminosos, } \\
\text { no caso do CGCS. Baixo conteúdo de } \mathrm{K}_{2} \mathrm{O} \text { c Rb, c trenils crescentes com a } \\
\text { diferenciação. }\end{array}$ & $\begin{array}{l}\text { CGCS: Rb-Sr (RT) - } 552 \pm 8 \mathrm{Ma} \text { c Ri }=0,70503 \pm 0,0003 \mathrm{~d} \\
\text { U-Pb (ZR): } 54 \text { I Ill - 561 } 56 \mathrm{Ma} \text {, c herança: } 1,9-2,4 \mathrm{Ga} \text { (fácies } \\
\text { evoluída)'; } 565 \pm 14 \mathrm{Ma} \text { a } 589 \pm 5 \mathrm{Ma}-64(\text { ) } \pm 16 \mathrm{Ma} \text { (borda/núcleo); e } \\
\text { herança: } 1,7-2,1 \mathrm{IGa} \text { e 2,6-2,8Ga (leucogranitos)' } \\
\text { eNd (6(X) Ma) = -19,5 (monzogr.) c - } 9,9 \text { (granod.) }\end{array}$ \\
\hline $\begin{array}{l}\text { II. Shoshoníticos: } \\
\text { Complexo Intrusivo Lavras do Sul (CILS): } \\
\text { Monzogranitos do núcleo } \\
\quad \text { Monzodiorilo Arroio do Jacques (JAC) }\end{array}$ & $\begin{array}{l}\text { Monzonilos c qz-monzonitos frequentes, com granodiorilos, mon/ogranitos c } \\
\text { monzodiorilos subordinados. Anfibólio é a fase varíctal mais saliente c } \\
\text { precoce na cristalização, c cuja composição é mais cálcica c magncsiana que } \\
\text { nos tipos alcalinos. Caracicri/am-sc pêlos altos teores de CaO, Sr c Ba c pêlos } \\
\text { padrões mais (racionados c menor conteúdo de ETR. Conteúdo mais elevado de }\end{array}$ & $\begin{array}{l}\text { CILS (núcleo): } \mathrm{Rb}-\mathrm{Sr}(\mathrm{RT})-608 \pm 54 \mathrm{Ma} \mathrm{c} \mathrm{Ri}=0,70415 \\
\pm 0,(\mathrm{KX}) 58^{\prime} \\
\text { U-Pb (ZR) - } 592 \pm 5 \mathrm{Ma} ; \mathrm{ENd}(6(\mathrm{X}) \mathrm{Ma})=-3,0^{4} \\
\mathrm{JAC}: \mathrm{Rb}-\mathrm{Sr}(\mathrm{RT})-630 \pm 66 \mathrm{Ma} \mathrm{c} \mathrm{Ri}=0,70533 \pm 0 . \mathrm{fXXÜ0^{5 }}\end{array}$ \\
\hline Maciço Granítico Santo António (MGSA) & $\mathrm{Rb} \mathrm{c} \mathrm{K} 2 \mathrm{O}$, relativo ao tipo anterior. & MGSA: $\mathrm{Rb}-\mathrm{Sr}(\mathrm{RT})-645 \pm 38 \mathrm{Mac} \mathrm{Ri}=0,70462 \pm 0,00026^{6}$ \\
\hline $\begin{array}{l}\text { III. Alcalinos: } \\
\text { Mctaluminosos fortemente alcalinos: } \\
\text { Pcitita granitos c sicnogranitos do CILS }\end{array}$ & $\begin{array}{l}\text { Porções associadas espacial e icmporalmcntc a granitóidcs de afinidade } \\
\text { shoshonítica (CILS) ou caldeu-alcalina alto K (QMT). Qz-sicnitos a qz- } \\
\text { monzonitos, sicnogranitos c FK-granitos, com anfibólios cálcicos frequentes. } \\
\text { Conteúdo elevado de Zr c tremls crescentes com a diferenciação; baixos valores } \\
\text { de CaO c altos de Rb c K,O. relativo aos tipos seguintes. Baixas razões Ba/Sr c } \\
\text { Y/Nb, que os assemelha aos granitos alcalinos do tipo A-1. }\end{array}$ & $\begin{array}{l}\text { CILS (alcalinos): Rb-Sr (RT) }-556 \pm 34 \mathrm{Mac} \mathrm{Ri}=0,70489 \pm 0,0020 \mathrm{tf} \\
\text { U-Pb (ZR) } 580 \pm 11 \mathrm{Ma} \text { com herança cm } 608 \pm 7 \mathrm{Ma}^{2} ; 580 \pm 7 \mathrm{Mac} \\
\text { herança: } 597 \pm 5 \mathrm{Ma}^{3} \\
\text { ENd }(6(\mathrm{X}) \mathrm{Ma})=-0.2^{4} \\
\text { QMT: }{ }^{207} \mathrm{~Pb}-{ }^{206} \mathrm{~Pb}(\mathrm{ZR})-554 \pm 26 \mathrm{Ma} \text { (idade aparente) }{ }^{7}\end{array}$ \\
\hline $\begin{array}{l}\text { Mctaluminosos sensu strícto: } \\
\text { Granito Jaguari (GJ) } \\
\text { Complexo Granítico São Scpé (CGSS) }\end{array}$ & $\begin{array}{l}\text { Corpos de dimensões balolilicas, com predomínio de biotita monzo c } \\
\text { sicnogranitos, havendo maior diversidade textura! c composicional no CGSS. } \\
\text { Comparados ao tipo anterior, exibem teores mais elevados de CaO, AlOi, Ba c } \\
\text { Y; baixos de } \mathrm{Zrc} \text { c trenilx decrescentes com a diferenciação; baixos de Rb c } \\
\text { maiores razões Ba/Sr c Y/Nb. Asscmclham-sc aos granitos do tipo A-2. }\end{array}$ & 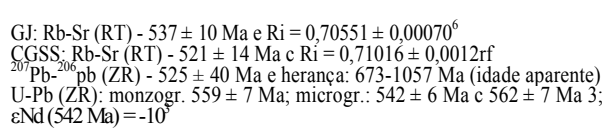 \\
\hline $\begin{array}{l}\text { Mctaluminosos particulares: } \\
\text { Complexo Granítico Ramada (CGR) }\end{array}$ & $\begin{array}{l}\text { Características gcoquímicas intermediárias entre os dois tipos alcalinos acima } \\
\text { descritos, destacando-se de ambos pêlos teores mais baixos de } \mathrm{Nb} \text { c maiores } \\
\text { ra/ôcs Ba/Sr c Y/Nb. Exibe baixo conteúdo de } \mathrm{Rb} \text { c mais elevado de } \mathrm{Zr} \text {. }\end{array}$ & CGR: Rb-Sr (RT) - $484 \pm 40 \mathrm{Ma}$ e $\mathrm{Ri}=0,71022 \pm 0,00150^{7}(?)$ \\
\hline
\end{tabular}

Referencias: 1- Sartori \& Kawashita(1985); 2- Leite (1995); 3- Remus e 7 - dados apresentados ou reinterpretados por Gastai et al. (1995a). analíticos, considerando na correção dos efeitos de discriminação de massa as razões ${ }^{86} \mathrm{Sr} /{ }^{88} \mathrm{Sr}=0,1194$ e ${ }^{146} \mathrm{Nd} /{ }^{144} \mathrm{Nd}=$ 0,7219 , e os valores para as constantes de desintegração de $\mathrm{iRb}$ $=1,42 \times 10^{-11} \mathrm{a}^{-1}$ e $1 \mathrm{sm}=6,54 \times 10^{-12} \mathrm{a}^{-1}$. Quando não ré ferido, os resultados isotópicos são apresentados com $2 \sigma$ de erro, efetuando-se as correções nos dados compilados.

Granito Jaguari O conjunto de 11 amostras (Fig. 5), analisadas pelo método $\mathrm{Rb}-\mathrm{Sr}$ (RT), alinha-se em uma boa isócrona fornecendo uma idade de $537 \pm 10 \mathrm{Ma}$ e ISr de $0,70551 \pm 0,00070$ (Fig. 6A, Tabela 2). Estes resultados confirmam a idade Rb-Sr de 4 amostras deste granito $(539 \pm$ $40 \mathrm{Ma}$ ), referida por Soliani (1986), havendo maior discordância quanto às razões iniciais $(0,7029)$. Estas divergências nas razões iniciais poderiam ser atribuídas ao deslocamento dos dados analíticos das 4 amostras em relação ao conjunto das demais, face à maior dispersão do conteúdo de $\mathrm{Rb}$ (vide Fig. 1 IA). Uma possível perturbação na sistema Rb-Sr é sugerida pela variação nos valores de ${ }^{87} \mathrm{Sr} /{ }^{86} \mathrm{Sr}(537 \mathrm{Ma})$ nas amostras das fácies mais diferenciadas, com altas razões $\mathrm{Rb} / \mathrm{Sr}$ (Tabela 2). Todavia, a ausência de transformações lexturais subsolidus significativas de baixa temperatura $\left(<400^{\circ}-450^{\circ} \mathrm{C}\right)$, nestas amostras, dificulta a interpretação de distúrbios mais efetivos no sistema isotópico, capazes de alterar a idade.

As idades isotópicas aparentes ${ }^{207} \mathrm{~Pb} /{ }^{206} \mathrm{~Pb}$, obtidas por evaporação de 4 cristais de zircão da amostra Kj 131, são de $565 \pm 55$ Ma (Tabela 3, Fig. 6B). No entanto, observa-se que os grãos individuais apresentam idades discrepantes, o que acarreta o aumento no erro e, em consequência, prejudica a confiabilidade do dado geocronológico. Em dois grãos obtiveram-se idades bem mais antigas (Kj 131/02 e 18), o que junto com o fato dos últimos blocos, por grão, apresentarem idades mais elevadas, permite especular sobre a presença de relictos de núcleos herdados. Neste caso, o componente de $\mathrm{Pb}$ herdado teria idade igual ou superior a $674 \pm 54 \mathrm{Ma}$, equivalente à média dos dados analíticos nos dois grãos referidos. Os outros dois cristais (Kj 131/3 e 4), em que os platôs estão melhor definidos (Fig. 6B), forneceram uma idade média de $544 \pm 23 \mathrm{Ma}$, mais coerente com o resultado Rb-Sr (RT).
Embora os resultados isotópicos $\mathrm{Rb}-\mathrm{Sr}$ e $\mathrm{Pb}-\mathrm{Pb}$ (monozircão) não sejam de todo conclusivos, apontam uma idade relativamente mais jovem (540 - $560 \mathrm{Ma}$ ) do Granito Jaguari, comparado a outros granitos da Suíte Intrusiva Saibro (Tabela 1). Desta forma, são confirmadas as relações de intrusão entre o Granito Jaguari e o pertita granito do Complexo Intrusivo de Lavras do Sul (Fig. 5), deduzidas a partir de mapeamento (Gastai \& Nardi 1992).

Complexo Intrusivo Lavras do Sul A redefinição do Complexo Granítico de Lavras, como caracterizado por Nardi (1984), incluiu os monzodioritos, monzonitos e quartzo monzonitos que ocorrem a norte, além da reinterpretação de suas fácies graníticas (Fig. 5). Visualiza-se este complexo como um centro magmático múltiplo, porém ao contrário de Nardi (1984), admite-se a contemporaneidade entre os eventos shoshoníticos e alcalinos supersaturados, com base nas relações de campo e feições texturais. Tal relação é confirmada pêlos resultados geocronológicos $\mathrm{U}-\mathrm{Pb}$, como indica $\mathrm{O}$ pequeno intervalo das idades dos dois conjuntos de granitos (» $12 \mathrm{Ma}$ ), com superposição dos valores se considerando o erro analítico (Tabela 1). Os granitóides shoshoníticos são as fácies dominantes (Fig. 5). São textural e composicionalmente diversificados, e sua evolução é equiparável às intrusões ressurgentes que caracterizam os eventos finais nos processos de subsidência de caldeiras (Gastai 1997). As fácies alcalinas são relativamente mais tardias e menos abundantes, dispondose nas bordas da estrutura.

FÁCIES GRANÍTICAS Na Figura 5 são localizadas as 21 amostras analisadas pelo método $\mathrm{Rb}-\mathrm{Sr}(\mathrm{RT})$, cujos resultados analíticos são apresentados ou compilados por Soliani (1986). Seguindo a sistemática de separação das fácies graníticas adotada por Nardi (1984), este autor obteve três idades distintas, correspondentes aos monzogranitos do núcleo (653 \pm 68 $\mathrm{Ma})$, ao granito transicional $(592 \pm 92 \mathrm{Ma})$ e ao pertita granito $(554 \pm 50 \mathrm{Ma})$. Fundamentados em critérios texturais e relações de campo, separou-se as fácies transicionais em dois conjuntos. Parte foi incorporada às fácies monzograníticas do núcleo do complexo e as demais individualizadas como 


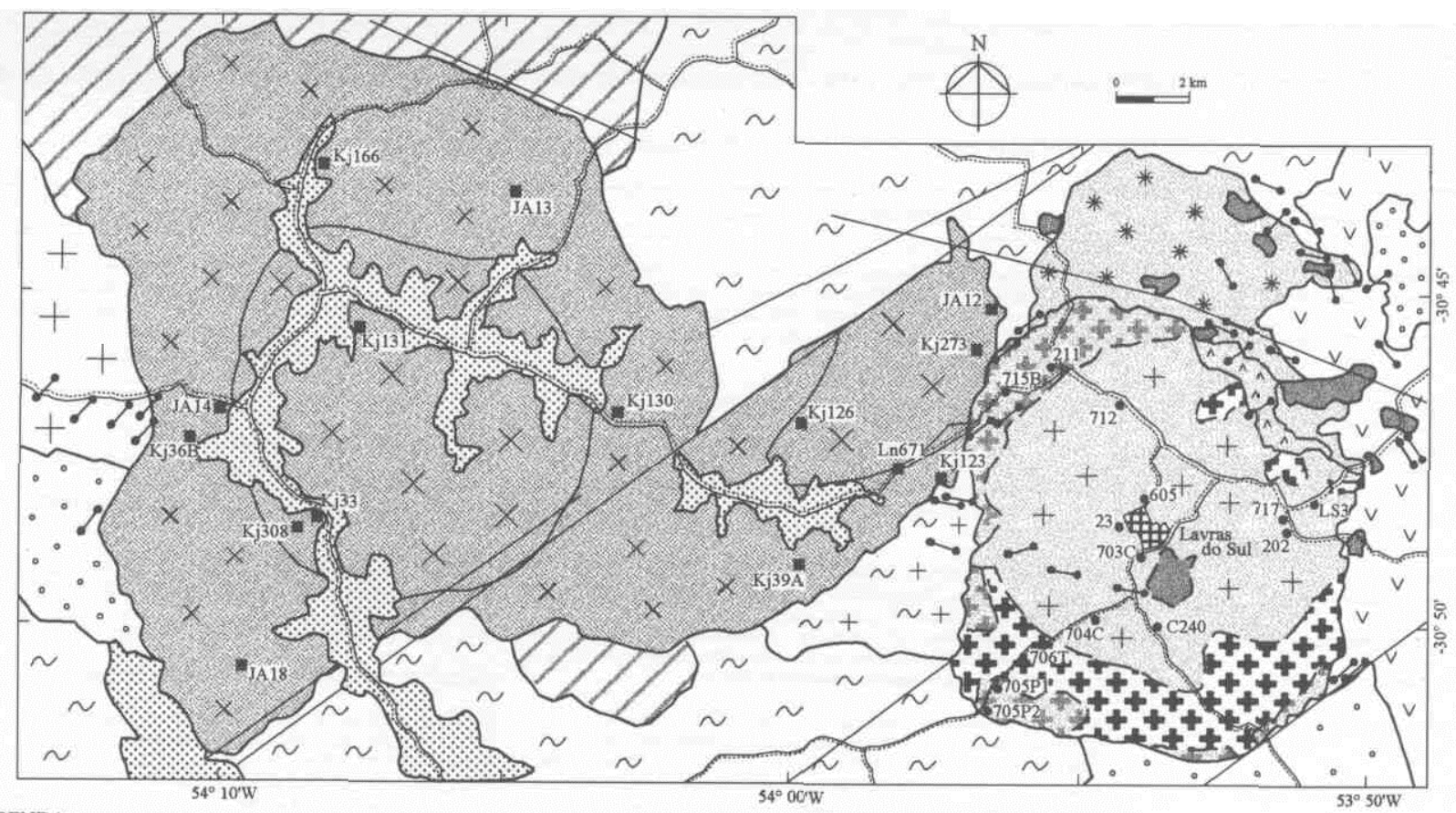

LEGENDA:

Coberturas gonduânica e terciária

Associaçåo plutono-vulcano-sedimentar: Neoproterozoico/EoPaleozóico

Complexo Intrusivo Lavras do Sul:
Sinito Jaguari:
X. Sienogranitos
Monzogranitos

Terrenos de medio a baixo grau - Neoproterozóico

W Granodiorito Fazenda do Posto

Gnaisses e granitóides do Complexo Cambai

Monzogranito Santa Rita

$\checkmark \vee$ Sequências vulcanogènicas - Formação Hilário

0 Sequências dominantemente sedimentares

$\sim$ Diques Falhas

Revista Brasileira de Geociências, Volume 28,1998

Figura 5 - Mapa geológico da região cio Granito Jaguari e Complexo Intrusivo Lavras do Sul, com a localização das amostras com dados isotópicos: $\mathrm{Rb}$-Sr (RT) e P b-Pb (zircão e feldspato).

Figure 5 - Geologic rnap of the region of the Jaguari Granitc and Lavras do Sul Intrusive Complcx, showing the localization of the samples with isotopic data: $\mathrm{Rb}-\mathrm{Sr}(\mathrm{RT})$ and $\mathrm{Pb}-\mathrm{Pb}$ (zircon and feldspar).

Tabela 2 - Resultados analíticos Rb-Sr do Granito Jaguari e Monzodiorito Arroio do Jacques.

Table 2 - Rb-Sr analytical results of the Jaguari Granite and Arroio do Jacques Monzodiorite.

\begin{tabular}{|c|c|c|c|c|c|c|c|c|}
\hline & $\begin{array}{c}\mathrm{Rb} \\
\mathrm{ppm}\end{array}$ & $\begin{array}{c}\text { St } \\
\text { ppm }\end{array}$ & $\mathrm{Rb} / \mathrm{Sr}$ & "RBRASt & $2 \sigma$ & "Strast & $2 \sigma$ & $" \mathrm{Sr} M \mathrm{MSr}(537)$ \\
\hline \multicolumn{9}{|c|}{ Granito Jaguari (GJ) } \\
\hline $\mathrm{Kj} 126 \cdot \mathrm{MH}$ & 171,8 & 163,4 & 1,05 & 3,048 & $\pm 0,096$ & 0,729042 & $\pm 0,000130$ & 0,70571 \\
\hline $\mathrm{K} / 308$ - MH & 150,0 & 135,8 & 1,10 & 3,204 & $\pm 0,098$ & 0,730028 & $\pm 0,000142$ & 0.70550 \\
\hline $\mathrm{K} \mid 273 \cdot \mathrm{MH}$ & 163,1 & 117,2 & 1,39 & 4,039 & \pm 0.126 & 0,736386 & $\pm 0,000156$ & 0,70546 \\
\hline $\mathrm{Kj} 33$ - MH & 158,9 & 109,8 & 1,44 & 4,198 & $\pm 0,128$ & 0,737662 & $\pm 0,000178$ & 0.70552 \\
\hline $\mathrm{K}_{\mathrm{j} 131}$-MM & 172,8 & 115,9 & 1,49 & 4,327 & $\pm 0,136$ & 0,738168 & $\pm 0,000184$ & 0,70504 \\
\hline $\operatorname{Ln} 671 \cdot$ SG & 161,9 & 73,2 & 2,21 & 6,430 & $\pm 0,200$ & 0,754871 & $\pm 0,000184$ & 0.70565 \\
\hline $\mathrm{K} j 36 \mathrm{~B}-\mathrm{SG}$ & 157,2 & 50,3 & 3,12 & 9,101 & $\pm 0,276$ & 0,775482 & $\pm 0,000378$ & 0,70582 \\
\hline K,123 - SG & 177,8 & 45,7 & 3,89 & 11,352 & $\pm 0,370$ & 0.790388 & $\pm 0,000340$ & 0,70349 \\
\hline Ki39A - SG & 143,8 & 23.6 & 6,00 & 17,888 & $\pm 0,554$ & 0,843884 & $\pm 0,000524$ & 0,70696 \\
\hline Kj166-SG & 131,1 & 16,0 & 8,17 & 24,064 & $\pm 0,714$ & 0,889152 & $\pm 0,000810$ & 0,70495 \\
\hline Kj130-SG & 150,5 & 16.5 & 9.12 & 26,906 & \pm 0.820 & 0,912834 & $\pm 0,000936$ & 0,70688 \\
\hline \multicolumn{9}{|c|}{ dados compilados por Soliani (1986) } \\
\hline JA13 & 152,6 & 1.06 & 3,070 & $\pm 0,172$ & 0,728700 & $\pm 0,003640$ & 0,70520 & \\
\hline JA12 & 106,7 & 1,93 & 5,590 & $\pm 0,314$ & 0,745100 & $\pm 0,003720$ & 0,70231 & \\
\hline JA14 & 66,3 & 2,06 & 5,990 & $\pm 0,336$ & 0,746100 & $\pm 0,003740$ & 0,70024 & \\
\hline JA18 & 13,5 & 7,69 & 21,887 & $\pm 1,226$ & 0,873600 & $\pm 0,004360$ & 0,70606 & \\
\hline \multicolumn{9}{|c|}{ Monzodioritos e monzonitos Arroio do Jacques (JAC) } \\
\hline Kс88 & 58,2 & 949,9 & 0,06 & 0,177 & $\pm 0,005$ & 0,706873 & $\pm 0,000148$ & \\
\hline Kс89 & 73.2 & 928,6 & 0,08 & 0.228 & $\pm 0,006$ & 0,707383 & $\pm 0,000126$ & \\
\hline KC419 & 105,4 & 814,3 & 0,13 & 0,374 & $\pm 0,011$ & 0,708289 & $\pm 0,000052$ & \\
\hline Ko411 & 116,9 & 916,7 & 0,13 & 0,369 & $\pm 0,011$ & 0,708596 & $\pm 0,000048$ & \\
\hline Ko417 & 110,1 & 833,1 & 0,13 & 0,382 & $\pm 0,011$ & 0,708940 & $\pm 0,000176$ & \\
\hline Kc92A & 127,5 & 886,4 & 0,14 & 0,416 & $\pm 0,013$ & 0.709053 & $\pm 0,000108$ & \\
\hline Kс413 & 138,5 & 957,3 & 0,14 & 0,419 & $\pm 0,013$ & 0,709283 & $\pm 0,000070$ & \\
\hline Kc155A & 127,2 & 777.1 & 0,16 & 0,474 & $\pm 0,014$ & 0.709558 & $\pm 0,000092$ & \\
\hline Kс421 & 142,6 & 809,8 & 0.18 & 0,510 & $\pm 0,016$ & 0,709666 & $\pm 0,000100$ & \\
\hline KC420 & 132,7 & 722,3 & 0,18 & 0,532 & $\pm 0,016$ & 0,709578 & $\pm 0,000030$ & \\
\hline \multicolumn{9}{|c|}{ Soliani (1986) } \\
\hline ESJ644 & 81,8 & 906,7 & 0,09 & 0,26 & $\pm 0,016$ & 0,707 & $\pm 0,0020$ & \\
\hline ESJ635a & 147,5 & 813,4 & 0,18 & 0,53 & $\pm 0,030$ & 0,7091 & $\pm 0,0026$ & \\
\hline
\end{tabular}

obs: fácies petrográficas do GJ: MH - monzogranitos heterogranulares; MM - monzogranilos médios e SG sienogranilos (Gastal 8 Nardi 1992). sienogranitos (Fig. 5). Esses últimos variam ate quartzo siemtos, c suas características composicionais permitem interpretá-los como termos menos diferenciados dos pertita granitos, o que c evidenciado nos diagramas químicos (Figs. 2A, 2C, 2E c $3 \mathrm{G}$ ) c pela composição dos anfibólios (Fig. 4). Considerando a nova subdivisão das fácies, obtiveram-se idades isotópicas $\mathrm{Rb}-\mathrm{Sr}(556$ - $608 \mathrm{Ma})$ dentro de intervalo mais restrito para os dois eventos magmáticos (Figs. 7A e B), mais consistentes com os resultados analíticos U-Pb (580 $592 \mathrm{Ma}$; Tabela 1). No entanto, os dois grupos de granitos, com diferentes afinidades geoquímicas (shoshonítica e alcalina), constituem conjuntos isotopicamente distintos em relação ao sistema $\mathrm{Rb}-\mathrm{Sr}$ (Fig. $7 \mathrm{C}$ ), reforçando a ideia de evoluções independentes, a partir de magmas parentais diversos, como advoga Nardi (1984). Tal proposição é corroborada pelo fato dos dois grupos constituírem trenas subparalelos em diagramas de correlação, como $\mathrm{CaO} /(\mathrm{Na} 2 \mathrm{O}+\mathrm{K} 20)$ versus $\mathrm{SiO}_{2}$ (Figs. $2 \mathrm{~A}$ e $\mathrm{B}$ ) e $\mathrm{Ce} / \mathrm{Nb}$ versus $\mathrm{Y} / \mathrm{Nb}$ (Figs. 3E e F). Tais evidências dificultam, assim, aceitar a proposta de Vieira \& Soliani (1989) de evolução comum de todas as fácies graníticas deste complexo. Todavia, com relação à gênese, os dados gcoquímicos c isotópicos sugerem derivação a partir de fontes manlclicas similares (Fig. 3E, 3F e vide Fig. 13).

$\mathrm{Na}$ obtenção da idade Rb-Sr (RT) das fácies alcalinas deste complexo, excluiu-se a amostra LS-3 (Fig. 7A), devido à incerteza de sua correlação petrográfica com estas fácies dada à sua localização (Fig. 5). O alinhamento dos pontos experimentais na reta isocrônica é razoável, havendo melhoria nos resultados com a inclusão da amostra de sienogranito, com menor razão $\mathrm{Rb} / \mathrm{Sr}$ (ponto 706), quais sejam: $556 \pm 34 \mathrm{Ma} \mathrm{e}$ $\mathrm{ISr}=0,70489 \pm 0,00208$. No entanto, a maior dispersão nas razões ${ }^{87} \mathrm{Sr} /{ }^{86} \mathrm{Sr}$, para pequenas variações nos valores de ${ }^{87} \mathrm{Rb} /{ }^{86} \mathrm{Sr}$ (Fig. 7C), ou 1/ ${ }^{86} \mathrm{Sr}$ (vide Fig. 12B), sugere a 
interferência de outros processos além do fracionamento mineral, capazes de acarretar distúrbios no sistema isotópico $\mathrm{Rb}-\mathrm{Sr}$. Desta forma, a discrepância entre as idades Rb-Sr e $\mathrm{U}-\mathrm{Pb}$, constatada nas fácies alcalinas (556 e $580 \mathrm{Ma})$, pode ser entendida como devida ao rejuvenescimento da idade $\mathrm{Rb}-\mathrm{Sr}$, decorrente de processos tardi a pós-magmáticos.
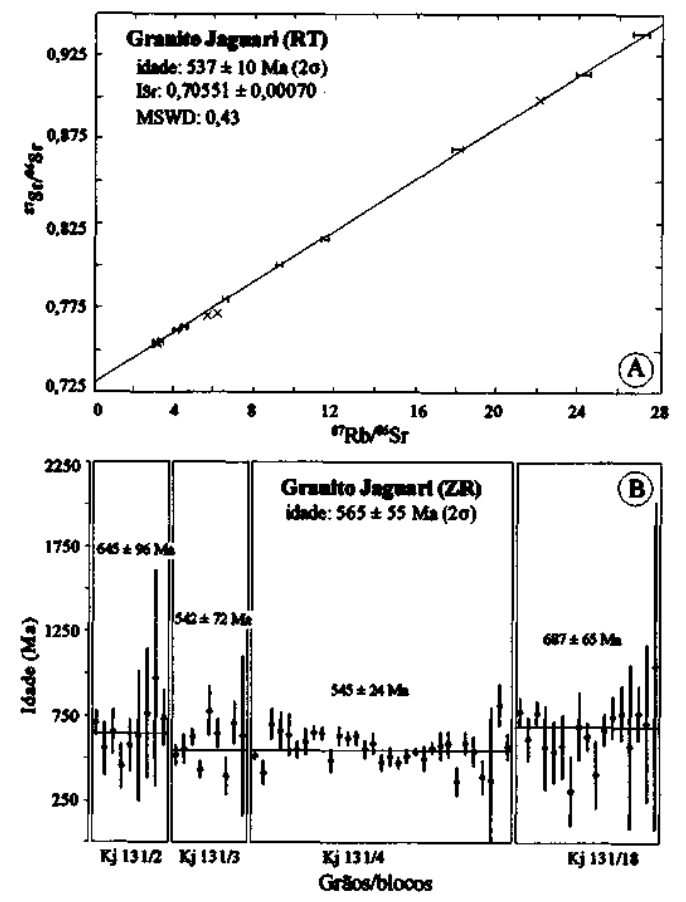

Figura 6 - Diagrama isocrônico Rb-Sr (RT) de amostras do Granito Jagnari - (A), exibindo pontos analíticos de 4 amostras (+), apresentados por Soliani (1986); e (B) - Resultados analíticos e idades aparentes $\mathrm{Pb} / \mathrm{Pb}$ de 4 cristais de zircão da amostra Kj 131.

Figure 6 - Isochron Rb-Sr (RT) diagram for samples of the Jaguari Granite (A), showing the analytical points of 4 samples $(+)$ prescnted by Soliani (1986); and (B) -Analytical results, and ${ }^{207} \mathrm{~Pb}{ }^{206} \mathrm{~Pb}$ apparent ages for4 zircon crystals of the sample $\mathrm{Kj} 131$.

Tabela 3 - Razões isotópicas $\mathrm{Pb}-\mathrm{Pb}$ de zircão do Granito Jaguari e Complexo Granítico São Sepé, obtidas por evaporação.

Table 3 - $\mathrm{Pb}-\mathrm{Pb}$ isotopic ratios by single-zircon evaporation of the Jaguari Granite and São Sepé Granitic Complcx.

\begin{tabular}{|c|c|c|c|c|}
\hline Amostra & $N^{s}$ de análises & ${ }^{20+4} \mathrm{~Pb} / 000$ & ${ }^{207} \mathrm{~Pb}^{2001} \mathrm{~Pb}_{\mathrm{q}} 20$ & Idade (2o) \\
\hline \multicolumn{5}{|c|}{ Granito Jaguari - GJ (monzogranitos) } \\
\hline lg 131/02 & 54 & $0,000295 \times 0,000332$ & $0.06099 \pm 0.00272$ & $645=96$ \\
\hline Kj $131 / 03$ & 54 & $0,000180=0,000072$ & $0.05807 \pm 0.00189$ & $542=72$ \\
\hline KG $131 / 04$ & 186 & $0,000152 \pm 0,000002$ & $0,05828 \pm 0,00065$ & $545 \pm 24$ \\
\hline \multirow[t]{2}{*}{ kj 131/18 } & 102 & $0,000196 \pm 0,000224$ & $0,06202 \pm 0,00189$ & $687 \pm 65$ \\
\hline & $\mathbf{Y}=396$ & & & $565 \pm 55$ \\
\hline \multicolumn{5}{|c|}{ Complexo Cranifico \$So Seph - cGS\$ (monzogranitos) } \\
\hline Ks 263103 & 48 & $0,000157 \pm 0,000158$ & $0,07367 \pm 0,00429$ & $1057 \pm 122$ \\
\hline Ks $263 / 06$ & 30 & $0,000143 \pm 0,000764$ & $0,06306 \pm 0,00301$ & $713 \pm 102$ \\
\hline $\mathrm{K}_{\mathrm{s}} 263 / \mathrm{cg}^{*}$ & 60 & $0,000138 \pm 0,000090$ & $0,05859 \pm 0,00089$ & $555 \pm 33$ \\
\hline $\mathrm{Ks} 263 / 09$ & 30 & $0,000121 \pm 0,000176$ & $0,06226 \neq 0,00349$ & $695 \pm 119$ \\
\hline $\operatorname{Ks} 26,3 / 10^{+}$ & 78 & $0,000227 \pm 0,000194$ & $0,05820 \pm 0,00227$ & $555 \pm 85$ \\
\hline \multirow[t]{2}{*}{ Ks $263 / 11^{*}$} & 54 & $0,000043 \pm 0,000040$ & $0,05713 \pm 0,00076$ & $498 \pm 29$ \\
\hline & $\Sigma=192$ & & & $525 * 40$ \\
\hline
\end{tabular}

obs: * assinala cristais utilizados no cálculo da idade, no caso do CGSS; ${ }^{207} \mathrm{Pbl}{ }^{206} \mathrm{Pbc}$ - razões corrigidas do $\mathrm{Pb}$ comum, utilizando composição isolópica do $\mathrm{Pb}$ do modelo de Stacey \& Kramers (1975). Zircão em cristais euédrícos, com prisma (100), terminado por bipirãmide (101), bem desenvolvido. No GJ, presença de prisma (110) frequente, cristais transparentes e de dimensões regulares (C/L - 3:1); no CGSS, predominam formas simples e os cristais são ligeiramente rosados, transparentes a translú cidos e possuem dimensõ es variadas (C/L - 2:1 a 5:1).
Nas fácies do núcleo do complexo, a inclusão das três amostras com razões $\mathrm{Rb} / \mathrm{Sr}$ mais elevadas no cálculo das idades $\mathrm{Rb}-\mathrm{Sr}(\mathrm{RT})$ ocasiona modificação significativa no dado geocronológico (Fig. 7B), comparado ao resultado apresentado por Soliani (1986). Obteve-se, desta forma, idade mais jovem de $608 \pm 54 \mathrm{Ma}$ e ISr de 0,70415 $\pm 0,00058$. A dispersão dos pontos analíticos é maior nas amostras menos diferenciadas e localizadas na porção central (pontos 605,23 e 703c; Figs. 5 e 7C), próximo ao pequeno stock de quartzo monzonito
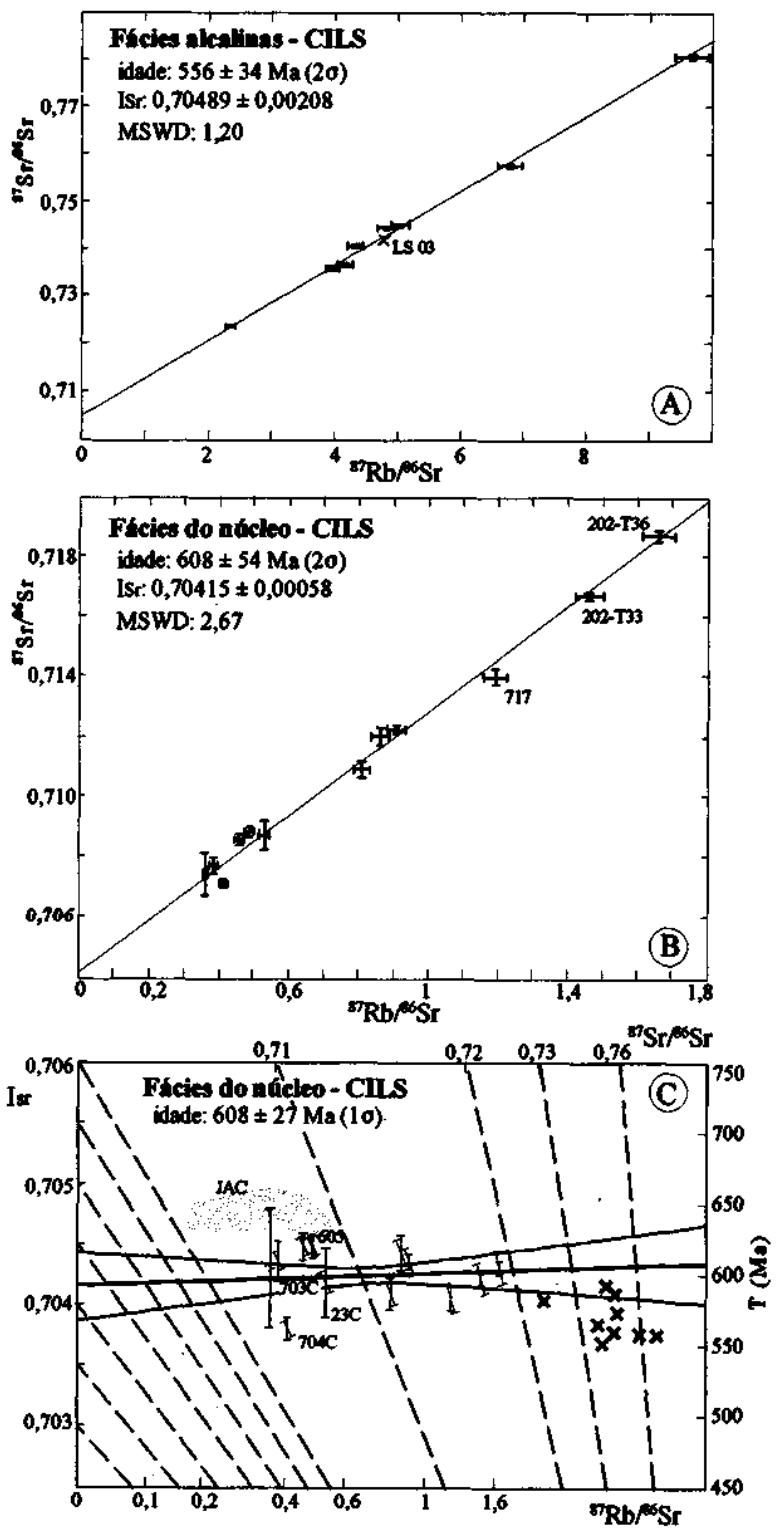

Figura 7 - Diagramas isocrônicos convencionais $R b-S r(R T)$ das fácies alcalinas - (A) e shoshoniticas - (B) do CILS, exibindo a reinterpretação dos dados analíticos de Soliani (1986), fundamentada na nova subdivisão das fácies; e (C) Best isochron diagram de amostras de diferentes fácies do CILS, com a idade Rb-Sr do núcleo do complexo; JAC Monzodiorito Arroio do Jacques (dados Tabela 2 e Fig. 8). Amostras referidas no texto estão identificadas. Figure 7 - Conventional isochron $\mathrm{Rb}-\mathrm{Sr}$ (RT) diagrams for the alkaline - (A), and shoshonitic - (B) fácies of the CILS, shown the reinterpretation of the analytical data after Soliani (1986), based on the new fácies subdivision; and (C) - Best isochron diagram for samples of different CILS fácies, with the $\mathrm{Rb}-\mathrm{Sr}$ age of the nucleus of the complex; JAC - Arroio do Jacques Monzodiorite (data in Tab.le 2 and Fig. 8). Samples referred in the text are identified. 
porfírítico. Poder-se-ia especular, assim, que a dispersão dos resultados analíticos $\mathrm{Rb}$-Sr, responsáveis pelo valor mais elevado do MSWD $(2,67)$, se deva a algum tipo de contaminação ou hibridismo, como sugerido também pelas texturas de desequilíbrio em amostras próximo a estes locais.

MONZODIORITO ARROIO DO JACQUES Constitui um corpo semicircular, composicionalmente zonado e que ocorre na porção centro-norte do Complexo Intrusivo Lavras do Sul (Fig. 5). Varia de monzodiorito com ortopiroxênio, situado próximo ao corpo granítico até monzonito. Nos lermos menos diferenciados, próximos às fácies graníticas, as texturas indicam reequilíbrios pós-magmáticos significativos, decorrentes provavelmente de efeitos térmicos ocasionados pela intrusão das mesmas. As características geoquímicas desta fácies, tais como baixas razões $\mathrm{FeO} /(\mathrm{FeO}+\mathrm{MgO})$, altos teores de $\mathrm{Sr}$ e padrões de ETR mais fracionados, permitem diferenciá-las dos monzodioritos do Complexo Anelar Leões, de afinidade moderadamente alcalina (Gastal et al. 1997). Tais feições aproximam-na do magmatismo shoshonítico, embora apresente valores mais baixos das razões $\mathrm{Y} / \mathrm{Nb}$ (Fig. 3F), similares ao de rochas lamprofíricas.

Em virtude do elevado valor dos erros analíticos e o deslocamento relativo aos demais pontos experimentais, os resultados de duas amostras apresentadas por Soliani (1986) não foram considerados no cálculo das idades Rb-Sr (Tabela 2 c Fig. 8B). Os baixos valores e a pequena variação nas razões $\mathrm{Rb} / \mathrm{Sr}$ dificultam a definição das idades. Além disso, a grande dispersão dos pontos analíticos, revelada também pêlos altos valores do MSWD $(3,4$ e 12,04), é indicativa de perturbações significativas do sistema isotópico, talvez relacionadas aos reequilíbrios pós-magmáticos referidos. Considerando o conjunto das 10 amostras, obteve-se a idade de $606 \pm 56 \mathrm{Ma} \mathrm{c} \mathrm{ISr}$ de 0,70534 $\pm 0,00031$ (Is) (Fie. 8B). Excluindo as duas amostras com menores razões $\mathrm{Sr} / \mathrm{Sr}$, os resultados são mais satisfatórios, com menor erro analítico: $630 \pm 66 \mathrm{Ma}$ e ISr de 0,70533 $\pm 0,00036$ (2s). Estas idades, embora devam ser encaradas com cautela, são consistentes com o fato desta fácies ser mais precoce ou, pelo menos, contemporânea ao núcleo do Complexo Intrusivo Lavras do Sul, como também sugerem as relações de campo. Os monzodioritos são secionados por diques de quartzo monzonito porfírítico, que também intrudem os monzonitos situados a norte e os monzogranitos do núcleo (Fig. 5).

Complexo Granítico São Sepé As relações de campo e a reavaliação dos dados petrográficos e geoquímicos das fácies dominantes no Complexo Granítico São Sepé levou a uma reinterprctação dos dados isotópicos $\mathrm{Rb}-\mathrm{Sr}(\mathrm{RT})$, apresentados por Sartori (1978), considerando a hipótese de cogeneticidade e, mesmo, comagmaticidade entre elas (Gastai et ai. 1995a). Sartori (1978) e Soliani (1986) tratam os resultados analíticos $\mathrm{Rb}$-Sr (RT) separadamente, obtendo idades distintas para cada conjunto de fácies, quais sejam: monzogranitos do núcleo -669 $\pm 108 \mathrm{Ma}$ e ISr de 0,7062 (Fig. 9B); sienogranitos periféricos $-527 \pm 14 \mathrm{Ma}$ e ISr de 0,7067; e intrusões menores ou microgranitos - 466 $\pm 12 \mathrm{Ma}$ e ISr de 0,7102 . Vlack \& Cordani (1986), ao reinterpretar estes dados, salientam que as idades mais jovens decorrem de distúrbios no sistema isotópico $\mathrm{Rb}-\mathrm{Sr}$, não tendo, portanto, significado geocronológico. As idades U-Pb obtidas, por Remus et al. (1997a), na amostra de monzogranito da parte norte do núcleo do complexo e de microgranito (Tabela 1), confirmam a proximidade temporal entre as diversas fácies (559-542 Ma), reforçando as premissas deduzidas a partir das relações de campo e feições petrográficas. Embora não haja dados analíti$\mathrm{cos}$ U-Pb dos sienogranitos, pode-se estimar uma idade muito próxima à das fácies do núcleo do complexo. No microgranito, Remus et al. (1997a) interpretam a idade U-Pb mais antiga (562 $\pm 7 \mathrm{Ma}$ ) como devida a grãos herdados de fácies precoces do complexo. Considerando que o microgranito amostrado situa-se cerca de $1 \mathrm{Km}$ para S-SE do ponto Ks 202 (Fig. 9A; M.V. Remus, informação oral) e ocorre como dique nos sienogranitos, é provável que os grãos herdados sejam representativos dessa fácies.

Uma série de questões petrológicas atrativas são reveladas pêlos dados isotópicos Rb-Sr deste complexo que, no entanto, dificultam a obtenção de idades confiáveis. A idade mais jovem de $490 \pm 16 \mathrm{Ma}$ (Fig. 9B), obtida com todos os pontos analíticos, se deve à rotação da reta isocrônica devido à inclusão de amostras dos microgranitos. Estas correspondem à fácies de borda do complexo (Fig. 9A), e apresentam altas razões $\mathrm{Rb} / \mathrm{Sr}$ e valores extremamente baixos de $\mathrm{Sr}$, o que as torna mais suscetíveis a perturbações do sistema isotópico (Hradetzky \& Lippolt 1993). Ademais, não se descartada a possibilidade de que parte desta fácies, em especial as amostras de diques, representem pulsos magmáticos tardios e de natureza mais marcadamente alcalina, como apontam as idades U-Pb (Tabela 1) e os dados geoquímicos.

Desconsiderando as cinco amostras de microgranitos, obtcve-se a idade $\mathrm{Rb}-\mathrm{Sr}$ de $521 \pm 14 \mathrm{Ma}$ e ISr de 0,71016 \pm 0,00126 (Fig. 9C). Embora o baixo valor do $\operatorname{MSWD}(0,86)$ testemunha o bom alinhamento dos pontos analíticos na reta isocrônica, os monzogranitos do núcleo do complexo formam um conjunto à parte (Fig. 9B), justificando o tratamento isolado que fornece uma idade mais antiga, como apresentado por Sartori (1978) e Soliani (1986). No entanto, tal resultado pode ser interpretado como linha ou isócrona de mistura, como sugerido pêlos diagramas de correlação $\mathrm{Sr} / \mathrm{Sr}(560)$ $\mathrm{X} 1 /{ }^{86} \mathrm{Sr}$ ou $\mathrm{Rb}$ discutidos adiante (vide Figs. $12 \mathrm{~A}$ e C). De fato, grande parte das amostras de monzogranito analisadas localizam-se na região onde há abundância de heterogeneidades texturais indicativas de mistura de magmas (Gastai

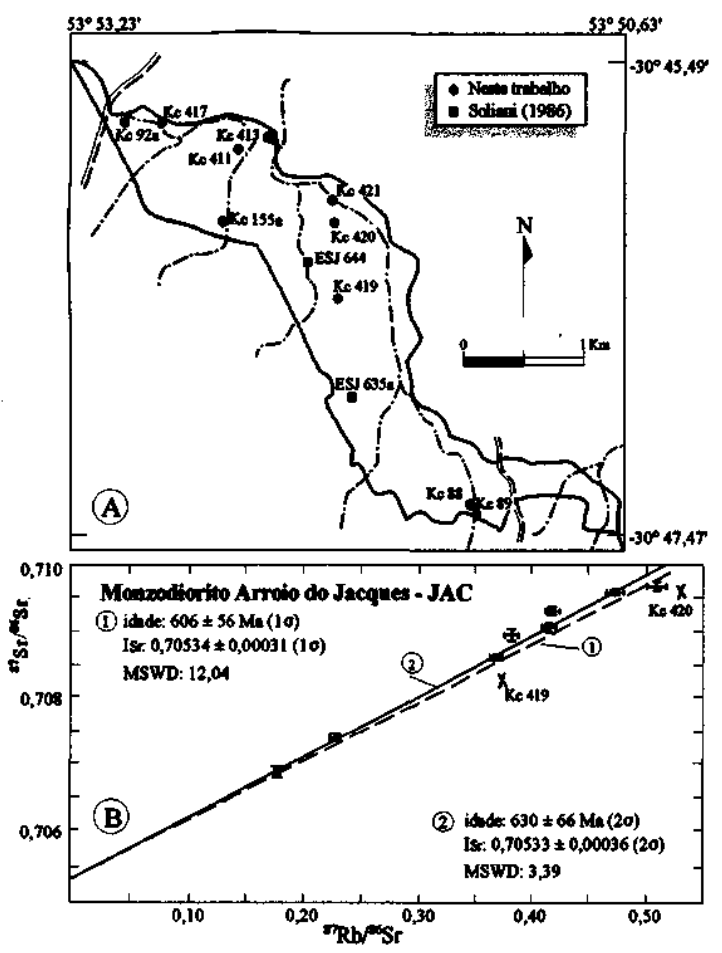

Figura 8 - Monzodiorito Arroio do Jacqnes - JAC(CILS): (A) - Localização das amostras com dados isotópicos Rb-Sr (RT); e (B) - Diagrama isocrônico convencional, mostrando as duas idades $\mathrm{Rb}-\mathrm{Sr}$ mencionadas no texto.

Figure 8 - Arroio do Jacques Monzodiorite - JAC (CILS): (A) - Localization of the samples with $\mathrm{Rb}-\mathrm{Sr}(\mathrm{RT})$ isotopic data; and (B) - Conventional isochron diagram, shown the two $\mathrm{Rb}-\mathrm{Sr}$ ages referred in the text. 
1997). Na evolução dos sienogranitos, a participação de processos capazes de alterar as razões isotópicas e a idade $\mathrm{Rb}-\mathrm{Sr}$ é também sugerida nestes diagramas de correlação. Tais processos podem ser atribuídos à maior atividade das fases voláteis nos estágios tardi a pós-magmáticos, retidas nas porções apicais e laterais da intrusão com a formação das cúpulas graníticas félsicas. Nos sienogranitos mais evoluídos, a importância das feições texturais indicativas das transformações subsolidus de alta e baixa temperatura corroboram esta interpretação (Gastai \& Ortiz 1997).

Os resultados isotópicos ${ }^{207} \mathrm{~Pb} /{ }^{206} \mathrm{~Pb}$, obtidos pela evaporação de cristais de zircão da amostra Ks 263, evidenciam a presença de grãos herdados, que forneceram idades aparentes de $695 \pm 119$ Ma a $1057 \pm 122$ Ma (Tabela 3; Fig. 9D). O crescimento constante e sistemático das idades ${ }^{207} \mathrm{~Pb} /{ }^{2} \mathrm{~Pb}$, como exemplificado no grão Ks-263/06, também constitui comportamento típico de herança. A idade aparente ${ }^{207} \mathrm{~Pb} /{ }^{206} \mathrm{~Pb}$ de $525 \pm 40 \mathrm{Ma}$, fornecida pela média de 3 grãos de zircão da amostra de monzogranito, é consistente com a idade $\mathrm{Rb}$-Sr das fácies dominantes neste complexo. No entanto, valores mais antigos são sugeridos em cristais (Ks 263/8 e 10) em que os platôs são melhor definidos (Fig. 9D). Nestes, obteve-se a idade média de $555 \pm 31 \mathrm{Ma}$, concordante com a idade U-Pb da fácies do núcleo (559 7 Ma; Tabela 1$)$.

Em resumo, os dados isotópicos $\mathrm{Rb}-\mathrm{Sr}(\mathrm{RT})$ e $\mathrm{Pb}-\mathrm{Pb}$ (monozircão) do Complexo Granítico São Sepé não são conclusivos com relação à idade. Os valores mais jovens obtidos pelo método $\mathrm{Rb}-\mathrm{Sr}$ (RT), discordantes dos resultados U-Pb, podem ser entendidos como evidência de distúrbios no sistema $\mathrm{Rb}-\mathrm{Sr}$. Todavia, com relação aos vestígios de componente de $\mathrm{Pb}$ herdado no zircão, é peculiar o fato de serem evidentes apenas em amostras do monzogranito da porção centro-sul do núcleo do complexo (Ks 263; Fig. 9A), onde são abundantes as feições texturais de hibridismo, como também testemunham os desequilíbrios no sistema isotópico $\mathrm{Rb}-\mathrm{Sr}$. O fato de não terem sido detectados componentes de $\mathrm{Pb}$ herdado, similares a estes, nas análises de SHRIMP apresentadas por Remus et al. (1997a), pode ser atribuído à maior homogeneidade composicional e textural dos monzogranitos porfiríticos amostrados, que situam-se na parte norte do núcleo do complexo.

$\mathrm{Pb}-\mathrm{Pb}$ comum em feldspatos do Granito Jaguari e Complexo Granítico São Sepé Apesar das razões isotópicas $\mathrm{Pb}-\mathrm{Pb}$ de ambos os granitos serem relativamente homogéneas, a amostra $\mathrm{Kj} 130$ do Granito Jaguari destaca-se pêlos valores mais elevados (Tabela 4 e Fig. 10). Esta amostra representa os termos mais evoluídos dos sienogranitos, em que ocorre maior dispersão nas razões isotópicas ${ }^{87} \mathrm{Sr}{ }^{86} \mathrm{Sr}(537)$ (Tabela 2) e onde as texturas dos feldspatos indicam uma maior atividade dos processos pós-magmáticos de alta temperatura $\left(450^{\circ}-650^{\circ} \mathrm{C}\right)$. Paradoxalmente, as amostras do Complexo Granítico São Sepé, incluindo tanto ortoclásio como microclínio, exibem razões isotópicas do $\mathrm{Pb}$ homogéneas (Tabela 4). No entanto, a presença de microclínio, neste caso, ocorre nos sienogranitos menos evoluídos e onde o ordenamento da fase feldspática é atribuído mais a efeitos térmicos, que à circulação de fluídos (Gastai \& Ortiz 1997).

Ambos granitos apresentam diferenças significativas na composição isotópica do $\mathrm{Pb}$ em feldspato (Fig. 10), como evidenciam também as razões ${ }^{207} \mathrm{~Pb} /{ }^{-6} \mathrm{~Pb}$ (Tabela 4). Todavia, em ambos, as razões isotópicas são inferiores aos valores da média do $\mathrm{Pb}$ crustal para uma idade de 500-600 Ma (Fig. 10B), segundo o modelo de Stacey \& Kramers (1975). Tal comportamento indica a contribuição de fontes distintas, mas similarmente menos radiogênicas, na geração de seus magmas parentais. No Complexo Granítico ^São Sepé, os valores extremamente baixos das razões $\mathrm{Pb} / \mathrm{Pb}$ e ${ }^{206} \mathrm{~Pb} / \mathrm{Pb}$ sugerem o envolvimento de componentes crustais com longa história evolutiva contendo baixo $L$ $\left({ }^{238} \mathrm{U} /{ }^{204} \mathrm{~Pb}\right)$. As maiores razões ${ }^{207} \mathrm{~Pb} /{ }^{206} \mathrm{~Pb}$ deste complexo, relativo ao Granito Jaguari, são consistentes com fontes mais antigas em sua gênese (Tabela 4). Isto permite especular a participação de rochas infracrustais paleoproterozóicas, talvez equivalentes ao Complexo Granulítico Santa Maria Chico, cujos resultados isocrônicos $\mathrm{Pb}-\mathrm{Pb}$ fornecem idade entre $2183+2 \mathrm{~S} 5 /-355$ e $2541+167 /-189$ e valores de $\mu$. variáveis, de 7,85 a 8,10 (Soliani 1986). Da mesma forma, segundo o modelo Plnmbotectonic IV (Zartman \& Haines 1988), as razões iniciais $\mathrm{Pb}-\mathrm{Pb}$ dos sienogranitos do Complexo Granítico São Sepé são consistentes com a evolução do $\mathrm{Pb}$ na crosta inferior, com baixo $\mu$ (Fig. 10A), mas relativamente alto $\mathrm{k}\left({ }^{232} \mathrm{Th} /{ }^{238} \mathrm{U}\right.$ ) (Fig. 10C). Por outro lado, as razões isotópicas iniciais do $\mathrm{Pb}$ no Granito Jaguari são mais elevadas, acomodando-se segundo as curvas de evolução do $\mathrm{Pb}$ próximas aos valores da crosta superior ou do manto modificado por subducção (Fig. 10A). Todavia, uma possível contribuição da crosta inferior é sugerida na figura $10 \mathrm{C}$, face às razões ${ }^{208} \mathrm{~Pb} /{ }^{206} \mathrm{~Pb}$ mais elevadas, indicativas de fontes relativamente toriogênicas $(>\mathrm{k})$. As razões isotópicas do $\mathrm{Pb}$ deste granito poderiam alternativamente ser relacionadas à uma possível curva de evolução do manto enriquecido, tipo EMI, como sugerido nas figuras $10 \mathrm{~A}$ e $\mathrm{C}$.

$\mathrm{O}$ Granito Jaguari possui razões isotópicas do $\mathrm{Pb}$ muito similares às obtidas, por Remus et al. (1997b), em pirita de zonas mineralizadas do pertita granito do Complexo Intrusivo Lavras do Sul (bloco Butiá) e nas vulcânicas da Formação Hilário (Fig. 10B). Estes autores interpretam o alinhamento dos resultados analíticos $\mathrm{Pb}-\mathrm{Pb}$ da pirita e de rocha total dos granitos deste complexo e de vulcânicas cogenéticas como evidencia da origem das mineralizações a partir de fluídos ortoderivados. Contudo, é evidente na figura $10 \mathrm{~B}$, que ao contrário do Granito Jaguari, as razões isotópicas do $\mathrm{Pb}$ da pirita estão muito próximas da curva de evolução do $\mathrm{Pb}$ em um reservatório com fi ligeiramente inferior à média crustal para uma idade de $600 \mathrm{Ma}$, segundo modelo de Stacey \& Kramers (1975). Uma idade mais jovem da fonte do Pb na nirita pode ser inferida também a partir das menores razões ${ }^{207} \mathrm{p}_{\mathrm{b}}{ }^{206} \mathrm{p}_{\mathrm{b}}(\mathrm{O}, 89 \mathrm{e} 0,90)$, comparadas às do Granito Jaguari (Tabela 4). $\mathrm{O}$ alinhamento entre os pontos analíticos de feldspato do Granito Jaguari, e de pirita e em RT das fácies graníticas do Complexo Intrusivo Lavras do Sul e vulcânicas correlatas permite ainda especular como possível fonte comum o manto enriquecido, tipo EMI (Fig. 10A e B). Neste caso, a geração dos magmas parentais do GJ teria ocorrido com maior participação de fonte infracrustal, ou de reservatório crustal menos radiogênico numa mistura de magmas mantélicos e crustais.

DISCUSSÃO Gênese e evolução dos granitos metaluminosos da Suíte Intrusiva Saibro A correlação entre as razões ${ }^{87} \mathrm{Sr} /{ }^{86} \mathrm{Sr}$ atuais e $1 /{ }^{86} \mathrm{Sr}$ ilustra os trenas evolutivos dos diferentes corpos graníticos, refletindo as variações nos valores de $\mathrm{Rb}$ e $\mathrm{Rb} / \mathrm{Sr}$ (Figs. 1 IA e B). A maior variação e dispersão dos teores de $\mathrm{Rb}$ e $\mathrm{Sr}$ (Fig. 1 IA), no Complexo Granítico São Sepé, sugere a participação de outros mecanismos de diferenciação, além do fracionamento mineral. A contaminação paralela ao fracionamento (processos AFC) é uma das possíveis explicações para o crescimento pronunciado das razões ${ }^{87} \mathrm{Sr} /{ }^{86} \mathrm{Sr}$ neste complexo (Fig. $11 \mathrm{~B}$ ). Nas fácies mais evoluídas do mesmo e nos termos alcalinos do Complexo Intrusivo Lavras do Sul, o decréscimo abrupto nos valores das razões ${ }^{87} \mathrm{Sr} /{ }^{86} \mathrm{Sr}(\mathrm{t})$, no sentido da evolução (Figs. 12A, B e C), caracteriza os distúrbios no sistema $\mathrm{Rb}-\mathrm{Sr}$ decorrentes da maior atividade das fases fluidas nos estágios tardi- a pós-magmáticos. Em ambos casos, tais distúrbios, embora em imensidades variadas, são responsáveis pelo rejuvenescimento das 'idades isotópicas $\mathrm{Rb}-\mathrm{Sr}$. No Granito Jaguari, estes processos não foram aparentemente efetivos o 
suficiente para ocasionar perturbações significativas do sistema isotópico (Tabela 2). Por outro lado, as idades $\mathrm{Rb}-\mathrm{Sr}$ mais antigas das fácies menos evoluídas de ambos complexos (CGSS e CILS), podem ser atribuídas ao crescimento das razões $\mathrm{Sr} / \mathrm{Sr}(\mathrm{t})$ no sentido da diferenciação (Fig. 12), devido a hibridismo. No Complexo Granítico São Scpé, as amostras de monzogranito acomodam-se segundo linhas de mistura simples (manto-crosta), em diagramas de correlação ${ }^{87} \mathrm{Sr} /{ }^{86} \mathrm{Sr}(560) \times 1 /{ }^{86} \mathrm{Sr}$ ou $\mathrm{Rb}$ (Fig. 12A e C), sugerindo que tais resultados representam linha ou isócrona de mistura (Zheng 1989). No Complexo Intrusivo Lavras do Sul, a pequena variação nas razões ${ }^{87} \mathrm{Sr} /{ }^{86} \mathrm{Sr}(585)$ de amostras de monzogranito situadas na porção central do núcleo do complexo pode ser decorrente da contaminação com líquidos quartzo monzoníticos, como aventado anteriormente.

$\mathrm{O}$ diagrama $\mathrm{Ce} / \mathrm{Nb}-\mathrm{Y} / \mathrm{Nb}$ evidencia a zonalidadc entre os granitos metaluminosos da Suíte Intrusiva Saibro (Fig. 3E), onde a composição das fácies alcalinas do Complexo Intrusivo Lavras do Sul é compatível com fontes mantélicas, e o Granito Jaguari e Complexo Granítico São Sepe incluem sucessivamente maiores contribuições crustais. Esta zonalidadc está também traduzida no comportamento das razões $\mathrm{CaO}$ /álcalis (Fig. 2A), Ba/Sr (Fig. 3G) e Zr/Nb (Fig. 3H), justificando a separação dos dois conjuntos de granitos: metaluminosos fortemente alcalinos e s.S., equivalentes respectivamente aos granitos A-1 e A-2 (Eby 1990). Diferentes graus de participação crustal, nos tipos metaluminosos s.s. desta suíte (GJ e CGSS), são inferidos pêlos dados isotópicos $\mathrm{Pb}-\mathrm{Pb}$, que também sugerem envolvimento de segmentos crustais distintos (Fig. 10). A participação mais efetiva da crosta na gênese do Complexo Granítico São Sepé é também demonstrada pela presença de componente de $\mathrm{Pb}$ herdado, em cristais de zircão dos monzogranitos (Fig. 9D), e por ENd com alto valor negativo nos microgranitos (Tabela 1; Remus et al. 1997a). Os altos teores de sílica das fácies deste complexo e a sua composição ligeiramente cálcicae hidratada também corroboram esta hipótese. $\mathrm{O}$ diagrama $\mathrm{Ce} / \mathrm{Nb}-\mathrm{Y} / \mathrm{Nb}$ evidencia, ainda, a correlação dos trends evolutivos dos dois conjuntos de granitos metaluminosos da Suíte Intrusiva Saibro, com os monzodioritos do Complexo Anelar Leões e microdioritos Armeiras (Fig. 3E), fortalecendo a ideia de que tais composições representam os magmas parentais dominantes desta suíte. As composições básicas a intermediárias possuem razões $\mathrm{Y} / \mathrm{Nb}$ similares a de basaltos moderadamente alcalinos, embora os valores mais elevados das razões $\mathrm{Ce} / \mathrm{Nb}$ e de $\mathrm{Ba}$ indicam
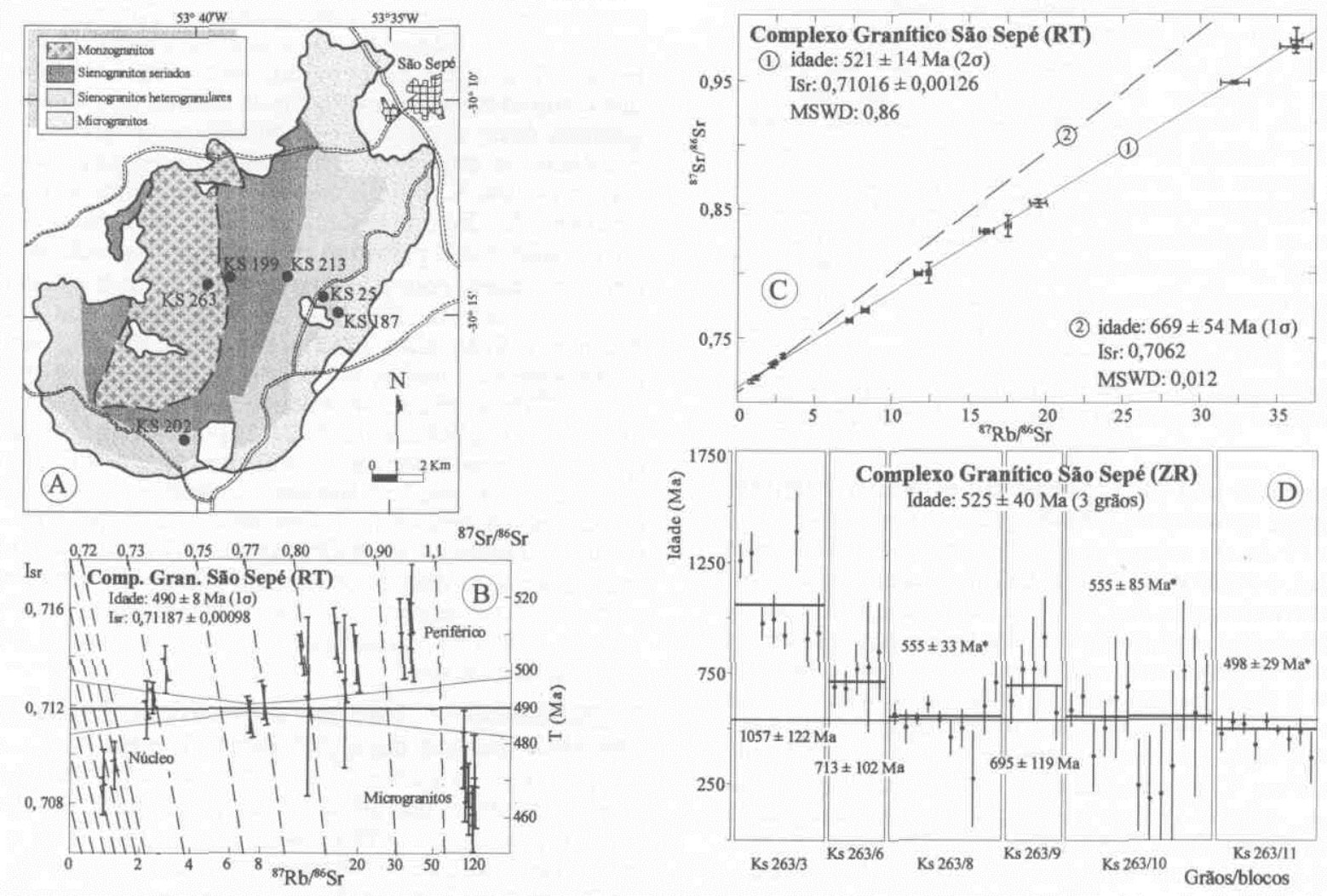

Figura 9 - Complexo Granítico São Sepé (CGSS): (A) -Localização das amostras analisadas para Pb-Pb (zircão e feldspato), com a nova interpretação das fácies petrográficas; (B) - Best isochron diagram dos três grupos de fácies, e a idade Rb-Sr do conjunto todo; (C) -Diagrama isocrônico convencional Rb-Sr (RT) das duas fácies dominantes (monzogranitos do núcleo e sienogranitos periféricos), excluindo os microgranitos (1); é mostrado também o alinhamento dos pontos analiticos das amostras do núcleo do complexo (2), que fornece idade bem mais antiga (Soliani 1986); e (D) - Resultados analiticos e idades aparentes ${ }^{207} \mathrm{~Pb}{ }^{206} \mathrm{~Pb}$ de 6 cristais de zircão da amostra $\mathrm{Ks} 263$, representativa dos monzogranitos do núcleo do complexo. A idade aparente desta amostra equivale à média dos resultados de três cristais de zircão assinalados por " * ".

Figure 9 - São Sepé Granitic Complex (CGSS): (A) -Localization of the samples analyzed for Pb-Pb (zircon and feldspar), with the new petrographic fácies subdivision; (B) - Best isochron diagram for the three groups of fácies, and the Rb-Sr age for ali fácies; $(\mathbf{C})$ - Conventional isochron $\mathrm{Rb}-\mathrm{Sr}(\mathrm{RT})$ diagram for the two dominant fácies (monzogranites from the nucleus. and peripheral syenogranites), without the microgranites (1); it is also shown thejmear ${ }^{\wedge}$ rray of analytical points of the samples from the nucleus of the complex (2), which provides an oldest age (Soliani 1986); e (D) - Analytical results, and ' $\mathrm{Pb} / "$ 'Pb apparent ages of six zircon crystals of the sample Ks 263, which is representative of the nucleus monzogranites. The apparent age of this sample is the average of the results for the three highlighted $\left(^{*}\right)$ crystals. 
fontes mantélicas ricas em elementos incompatíveis (Figs. 3E eG).

O Complexo Granítico Ramada apresenta feições geoquímicas peculiares, que sugerem a mistura de líquidos graníticos com magmas básicos distintos (Fig. 3E). O envolvimento de rochas infracrustais em sua gênese é também proposto, por Naime \& Nardi (1991), para explicar sua natureza ímpar. A composição dos dioritos deste complexo, ao contrário dos demais termos básicos a intermediários da Suíte Intrusiva Saibro, indica derivação a partir de manto empobrecido por processos prévios de fusão parcial, análogo ao de ambientes de subducção. Nas fácies eraníticas, o baixo conteúdo de $\mathrm{Rb}$ e as menores razões ${ }^{87} \mathrm{Sr} /{ }^{86} \mathrm{Sr}$ (Figs. 11A e B) apontam o envolvimento de fontes pobres em $\mathrm{Rb}$, corroborando uma possível contribuicão infracrustal. $\mathrm{O}$ valor relativamente alto da razão $\left({ }^{87} \mathrm{Sr} /{ }^{86} \mathrm{Sr}\right) \mathrm{j}$, e a idade isotópica $\mathrm{Rb}-\mathrm{Sr}$ mais jovem (Tabela 1) foram considerados suspeitos, por Gastai et al. (1995a), face à dispersão dos pontos analíticos na reta isocrônica. Tal dispersão sugere a superposição de trenas, decorrentes talvez de mistura de magmas com diferentes filiações e razões $\left.{ }^{87} \mathrm{Sr} /{ }^{86} \mathrm{Sr}\right) i$ contrastantes, o que é consistente com as heterogeneidades composicionais e texturais observadas (Gastai 1997).

As diferenças quanto aos registros de herança em cristais de zircão podem ser genericamente atribuídas a variações na alcalinidade dos magmas e na preservação de desequilíbrios texturais e composicionais, além dos fatores relativos ao grau de contribuição crustal. $\mathrm{O}$ aumento da alcalinidade favorece a destruição das evidências de componente de $\mathrm{Pb}$ herdado em zircão, à medida que aumenta sua solubilidade nos magmas (Watson \& Harrison 1983). Nesse sentido, a maior abundância destes registros é esperada em granitos de composição metaluminosa e cálcico-alcalina, associados à heterogeneidades composicionais importantes, como é o caso do Complexo Granítico Caçapava do Sul (Tabela 1). Por outro lado, os dados disponíveis sugerem que nos granitos metaluminosos e alcalinos, tais registros são preservados apenas nas fácies com maior desequilíbrio textural e composicional, como é o caso dos monzogranitos heterogranularcs do centro-sul do Complexo Granítico São Sepé (Fig. 9A), e são pouco evidentes em corpos mais homogéneos como o Granito Jaguari (Fig. 6B). Tal raciocínio não se aplica às fácies graníticas do Complexo Intrusivo Lavras do Sul, na medida em que não foram detectados vestígios de herança do $\mathrm{Pb}$, tanto em cristais de zircão dos monzogranitos metaluminosos do núcleo do complexo, como de suas fácies alcalinas (Tabela 1). Neste caso, os resultados permitem elaborar duas alternativas. Ambos con-

Tabela 4 - Resultados analíticos Pb-Pb comum de feldspatos do Granito Jaguari e Complexo Granítico São Sepé.

Table $4-\mathrm{Pb}-\mathrm{Pb}$ common analytical results of the feldspars of the Jaguari Granite and São Sepé Granitic Complex.

\begin{tabular}{|c|c|c|c|c|}
\hline Amostra & ansptroupt 10 & $207 \mathrm{~Pb} / 204 \mathrm{~Pb}$ ro & mapbpospb la & ${ }^{20 T} \mathrm{~Pb}$ \\
\hline \multicolumn{5}{|c|}{ Granito Jaguari -GJ } \\
\hline$K \mathcal{K} 131-\mathrm{MM}(\mathrm{O})$ & $16,348 \pm 0,010$ & $15,365 \pm 0,014$ & $36,469 \pm 0,0444$ & $0,936953 \pm 0,000024$ \\
\hline $\mathrm{KG} 39.56(0)$ & $16,480 \pm 0,010$ & $15,387 \pm 0,014$ & $36,604 \pm 0,044$ & $0,932716 \pm 0,000018$ \\
\hline Kj $130 \cdot$ SG (O") & $16,523 \pm 0,010$ & $15,446 \pm 0.014$ & $36,800 \pm 0,044$ & $0,933819 \pm 0,000070$ \\
\hline \multicolumn{5}{|c|}{ Complaxo Granitico sao Sept - CGSS } \\
\hline Ks $199-$ SS (M) & $15,312 \pm 0,009$ & $14,999 \pm 0.013$ & $35,804 \pm 0,043$ & $0,978579 \pm 0,000067$ \\
\hline Ks $202-5 S(0)$ & $15,423 \pm 0,009$ & $15,025 \pm 0,014$ & $35,890 \pm 0,043$ & $0,973189 \pm 0,000049$ \\
\hline Ks $213-\$ S(M)$ & $15,341 \neq 0,009$ & $15,023 \pm 0,014$ & $35,851 \pm 0,043$ & $0,978245 \pm 0,000024$ \\
\hline Ks $25+\mathrm{SH}(\mathrm{O})$ & $15,348 \pm 0,009$ & $15,025 \pm 0,014$ & $35,858 \div 0,043$ & $0,977412 \pm 0,000019$ \\
\hline Ks $187-\mathrm{SH}(0)$ & $15,348 \pm 0,009$ & $15,033 \pm 0,014$ & $35,838 \pm 0,043$ & $0,978448 \pm 0,000020$ \\
\hline
\end{tabular}

Obs: razõ es isotó picas corrigidas com um fator de discriminação de massa de $0,12 \%$ por u.m.a. (exceto ${ }^{\wedge} \mathrm{PbWb}$ ); fácies petrogrà ficas do GJ vide tabela I, e para o CGSS: SS - sienogranitos grossos e SH - sienogranitos heterogranulares mé dios a finos; estado estrutural do feldspato, segundo Gastai \& Ortiz (1997), é assinalado entre parêntesis: O - ortoclá sio; O* - ortoclá sio metaestá vel; e M - microclínio intermediário. juntos de fácies derivaram de magmas parentais mantélicos com pequena contribuição crustal, ou a mistura entre componentes mantélico e crustal envolveu intensa homogeneização, seja em zonas de interação manto-crosta, seja em câmaras magmáticas mais rasas.

Conjuntos de granitos em função das rochas geradoras - setor oeste Os grupos de granitóides individualizados em função da composição e tipo de fonte, na porção oeste, distribuem-se, genericamente, em domínios transversais e podem ser caracterizados da seguinte forma:

GRANITÓIDES COM CONTRIBUIÇÃO CRUSTAL IMPORTANTE Situados no setor norte-nordeste (Caçapava do Sul - São Sepé). As diferenças entre granitos com contribuição crustal significativa, como é o caso dos complexos graníticos São Sepé e Caçapava do Sul, são ilustradas nas figuras 11B e 12. O último possui composição cálcico-alcalina alto $\mathrm{K}$, mas é contemporâneo ao CGSS (Tabela 1), e apresenta algumas características genéticas e evolutivas similares que merecem ser destacadas. Nos monzogranitos do Complexo Granítico São Sepé estão envolvidas fontes crustais mais radiogênicas (Rb-Sr) (Figs. 12A e C), enquanto nos sienogranitos, os processos de contaminação são sugeridos apenas pelo abrupto crescimento do $\mathrm{Rb}$, não explicado pelo fracionamento mineral (Fig. $11 \mathrm{~A}$ ). Contudo, as composições isotópicas do $\mathrm{Pb}$ de feldspato (Fig. 10) apontam o envolvimento de reservatórios crustais menos radiogênicos, como indicado pêlos baixos valores de $\mu$. A participação de segmentos da crosta média ricos em Sr/ Sr, análogos ao Gnaisse Encantadas (Fig. 12), mas pobres em $U$ e $T h$, pode ser uma alternativa de fontes crustais envolvidas na gênese deste complexo. Uma outra opção, incluiria a participação de segmentos crustais distintos, à semelhança do que ocorreu na evolução do Complexo Granítico Caçapava do Sul. Nesse complexo, a fácies granodiorítica apresenta maior dispersão e valores mais elevados das razões ${ }^{87} \mathrm{Sr} /{ }^{86} \mathrm{Sr}(560 \mathrm{Ma})$ (Fig. 12), e razões ${ }^{43} \mathrm{Nd} /{ }^{14} \mathrm{Nd}(560 \mathrm{Ma})$ relativamente mais elevadas (Fig. 13B), compatíveis também com uma possível crosta média. Nos monzogranitos, ambas razões são consistentes com o envolvimento de crosta isotopicamente similar aos granulitos, equivalentes a segmentos infracrustais. A diversidade e os valores das idades dos componentes de $\mathrm{Pb}$ herdado, em zircão deste complexo (Tabela 1), fortalecem a ideia da heterogeneidade dos segmentos crustais envolvidos na sua gênese. Desta forma, os dados isotópicos destes dois complexos (CGSS e CGCS) corroboram a existência de crosta heterogénea e mais antiga no setor nortc-nordeste da porção oeste (Fig. 1), como proposto por Babinski et al. (1996). Além disso, no caso do Complexo Granítico Caçapava do Sul é evidente que, no sentido da diferenciação, houve o envolvimento de segmentos cruslais sucessivamente menos radiogênicos, indicando evolução mais complexa e, talvez, policíclica, o que é consistente com as suas características petrológicas (Nardi \& Bitencourt 1989).

GRANITÓIDES COM FORTE CONTRIBUIÇÃO MANTÉLICA Situados no setor centro-leste (Lavras do Sul), onde se encontra a maior área de exposição das vulcânicas intermediárias de afinidade shoshonítica (Lima \& Nardi 1997). A semelhança nas concentrações de elementos incompatíveis e nas composições isotópicas, dos granitos metaluminosos fortemente alcalinos da Suíte Intrusiva Saibro e de afinidade shoshonítica, apontam no sentido de que ambos derivaram de fontes próximas, com participação importante do manto litosférico rico em elementos incompatíveis (Figs. 3E; 3F e 13). No diagrama $\varepsilon_{\mathrm{Nd}}-\varepsilon_{\mathrm{Sr}}$, amostras destes granitos plotam próximo à composição do manto primitivo e de reservatórios tipo EMI, acomodando-se segundo linha de enriquecimento do manto (Fig. 13A). Esta linha evidencia o deslocamento dos 

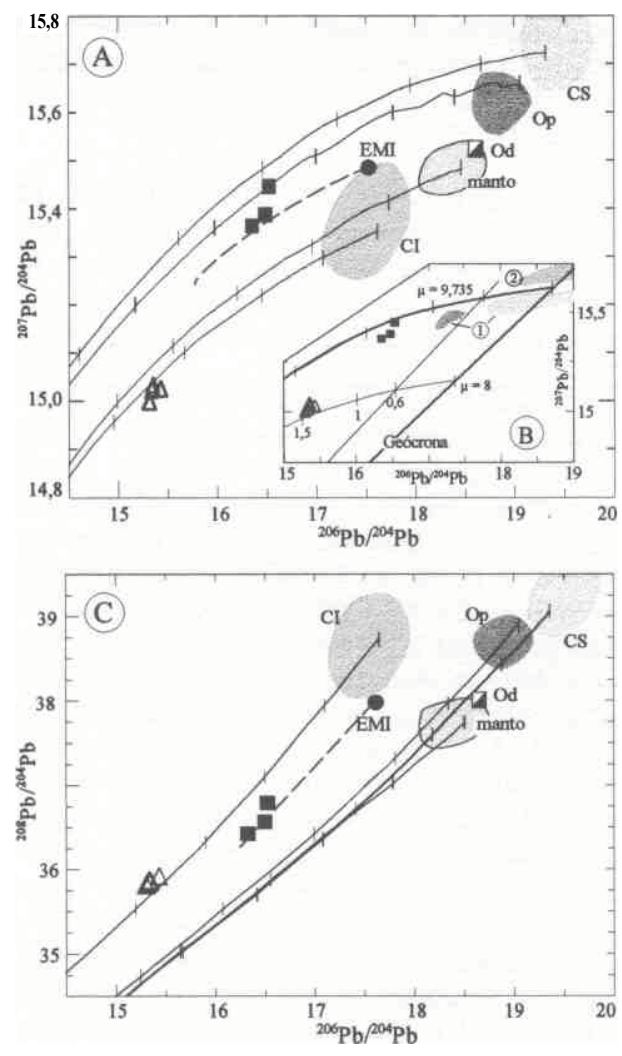

Figura 10- Evolução dos isótopos de Pb, segundo Plumbotectonics IV (Zartman \& Haines 1988) - (A e C), e em (B) segundo modelo de evolução em dois estágios (Stacey \& Kramers 1975), de amostras de feldspato do Granito Jaguari (quadrado cheio) e Complexo Granítico São Sepé (triângulo vazio). (A) - Diagramas ${ }^{207} \mathrm{~Pb}^{204}$, e $(\boldsymbol{C})^{208} \mathrm{~Pb}^{204} \mathrm{~Pb}$ versus ${ }^{206} \mathrm{~Pb}^{204} \mathrm{~Pb}$ exibem linhas de evolução do $\mathrm{Pb}$, com incrementos de 0,4 Ga, nos principais reservatórios fontes (Zartman \& Haines 1988): CI - crosta inferior; CS - crosta superior; $\boldsymbol{O d}$ - orogênico distai e $\boldsymbol{O} \boldsymbol{p}$-orogênico proximal; reservatório tipo EM I segundo Weaver (1991), e Unha tracejada esboça uma possível evolução para este tipo de fonte. (B) - Diagrama ${ }^{207} \mathrm{~Pb}^{204} \mathrm{~Pb}$ versus ${ }^{206} \mathrm{~Pb} /{ }^{204} \mathrm{~Pb}$, exibindo curvas de reservatórios, que evoluíram a partir de 3,7 Ga, com diferentes $\mu$ (Stacey \& Kramers 1975). As amostras de feldspato dos dois grani tos são comparadas a resultados obtidos para: 1) granitos do CILS e traquiandesitos correlatas (Remus et al. 1997b) (pirita -cinza escuro e RT - cinza claro); e 2) granitóides cálcico-alcalinos evoluídos do leste do escudo (RT - SGDF) e tipos equivalentes do Estado de Santa Catarina (Mantovani et al. 1987).

Figure $10-\mathrm{Pb}$ isotopic evolution for Plumbotectonics version IV (Zartman \& Haines 1988) - (A and C), and in (B) -for the two stages evolution modcl (Stacey \& Kramers 1975), for samples of feldspar of the Jaguari Granite (filled square), and São Sepé Granitic Complex (empty triangle). (A) $\left.{ }^{207} \mathrm{~Pb}\right|^{204} \mathrm{~Pb}$, and $(\mathrm{C}){ }^{208} \mathrm{~Pb}{ }^{204} \mathrm{~Pb}$ versus ${ }^{206} \mathrm{~Pb} /{ }^{204} \mathrm{~Pb}$ diagrams show the $\mathrm{Pb}$ evolution curves for the main source rcscrvoirs, with ticks at $0.4 \mathrm{Ga}$ intervals (Zartman \& Haines 1988): CI - lower crust; CS - upper crust; Od - distai orogene, and Op - proximal orogene; EM I reservoir after Weaver (1991), and dashed line outlines the possible evolution for this source type. (B) ${ }^{-207} \mathrm{pb} /{ }^{204} \mathrm{~Pb}$ versus ${ }^{206} \mathrm{pb} /{ }^{204} \mathrm{pb}$ diagram shown the curves for rescrvoirs which evolved with different $\mid j$ from an age of 3.7 Ga (Stacey \& Kramers 1975). The samples of feldspar from the two granites are compared with the following analytical results: 1) granites of the CILS and correlated trachy-andesites (Remus et al. 1997b) (pyrite -dark gray; and RT - light gray); and 2) highly evolved calc-alkaline granites from the east of the shield (RT -SGDF), and equivalent types from the Santa Catarina State (Mantovani et ai. 1987). reservatórios a partir do manto empobrecido (depleted mantle) $\mathrm{cm}$ direção a seu complemento (crosta inferior), indicando assim o sentido do enriquecimento (McKenzie \& O'Nions 1995). Entretanto, magmas derivados de mistura entre diferentes componentes mantélicos, ou mesmo entre reservatórios manlélicos e infracrustais também plotam próximo, ou segundo esta linha (e.g. McCulloch et al. 1983). Os modelos recentes de geração de magmas alcalinos associados à modesta extensão em regiões continentais envolvem a fusão parcial de manto litosférico (tipo MORB), previamente empobrecido pela extração de magmas basálticos, e subsequentemente enriquecido pela adição de líquidos metassomáticos, originados por pequenos percentuais de fusão parcial de fonte similar (McKenzie \& O'Nions 1995). Como discutem estes autores, o enriquecimento do manto litosférico é normalmente associado a eventos de subducção pretéritos, defasados em 1 a 2 Ga para que a assinatura isotópica ENd-esr do reservatório, então isolado, se torne a do manto EMI (Fig. 13). No entanto, a geração de reservatórios EMI é também explicada pela reciclagem, no manto, de sedimentos subductados (Weaver 1991), ou de material infracrustal (Zindler \& Hart 1986) durante eventos de subducção pretéritos.

Quanto à origem dos magmas alcalino (super)saturado e shoshonílico, em especial na região de Lavras do Sul, não existem argumentos sólidos, geoquímicos ou isotópicos, que permitam descartar a participação do manto enriquecido, como proposto também por Lima \& Nardi (1 997). Entretanto, o empobrecimento $\mathrm{cm}$ elementos fortemente controlados pelas fases acessórias residuais ( $\mathrm{Ti}, \mathrm{Nb}, \pm \mathrm{P}$ e $\pm \mathrm{ETRP})$, observado nas fácies básicas a intermediárias de ambos magmatismos, comparadas a associações alcalinas clássicas derivadas de fontes OIB (HIMU, EMI ou EMII), dificulta a derivação exclusiva a partir destes reservatórios, especificamente do tipo

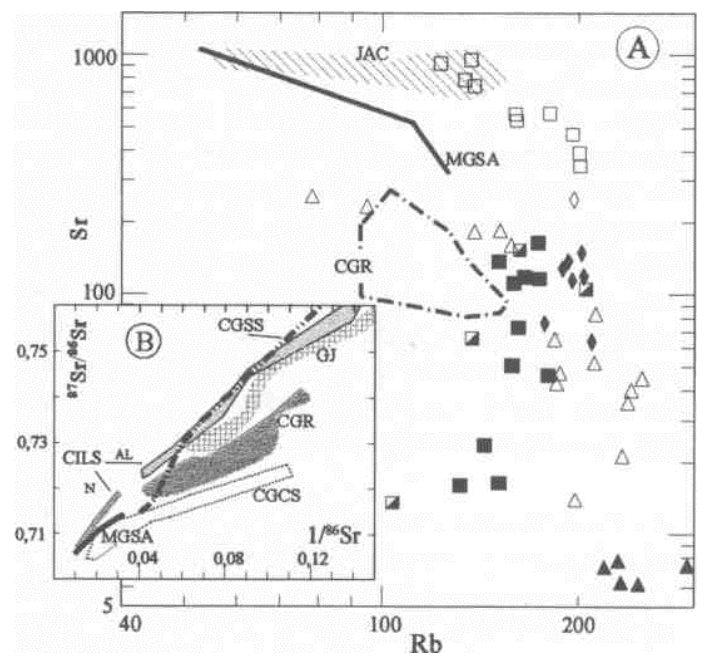

Figura 11 - Diagramas ilustrando o comportamento do sistema Rb-Sr nos granitóides da Suite Intrusiva Saibro (SIS), comparados a diversas associações graníticas da porção oeste: (A) - Sr versus Rb e (B) - ${ }^{87} \mathrm{Sr} /{ }^{86} \mathrm{Sr}$ aluai versus $1{ }^{86} \mathrm{Sr}$. Símbolos, siglas e referências, vide figura 2; e quadrado com preenchimento parcial - amostras do GJ com resultados isotópicos de Soliani (1986). Em (B), Complexo intriisivo Lavras do Sul - CILS: AL -fácies alcalinas e $N$-fácies do núcleo do complexo.

Figure 11 - Diagrams shown the Rb-Sr system behavior in the SIS granitoids compared with distinct granitic associations of the west sector: (A) Sr versus $\mathrm{Rb}$, and (B) $-{ }^{87} \mathrm{Sr} /{ }^{86} \mathrm{Sr}$ present versus $1 /{ }^{86} \mathrm{Sr}$. Symbols, abbreviations and references as in figure 2; and partial filled square - isotopic results of GJ samples after Soliani (1986). In (B), Lavras do Sul Intrusive Complex: AL -alkaline fácies, and $\mathrm{N}$ - nucleus fácies. 
EMI. Mesmo considerando o modelo que prevê o empobrecido prévio do manto litosférico, é difícil adequar a composição dos magmas parentais de ambos. Isto é mais evidente nas composições shoshoníticas, onde o efeito das fases acessórias residuais é mais proeminente (Gastai \& Nardi 1997). Resta saber se as características geoquímicas e isotópicas de ambos se devem a pequenas variações na contribuição crustal, ou à influência da subducção, via adição de fluidos oriundos da desidratação da placa subductada. Qualquer que seja o processo, a sucessão dos dois magmatismos (shoshonítico e alcalino) sugere a evolução, no tempo, nas fontes mantélicas e/ou nos processos de interação manto-crosta (câmaras infracrustais ou processos de delaminação). No caso dos granitos da Suíte Intrusiva Saibro é de particular importância a sua semelhança com as associações alcalinas de ambientes continentais (Figs. 2A, 2E e $3 \mathrm{H}$ ), em cuja origem tem sido admitida a contribuição de segmentos infracrustais (MacDonald 1994, Novak\&Mahood 1986). Além disso, mediante a interação manto-crosta é mais fácil o entendimento das feições genéticas e evolutivas dos dois magmatismos, como discutem Gastai \& Nardi (1997). Por outro lado, os termos shoshoníticos estão associados a lamprófiros e rochas intermediárias a básicas tipo Arroio do Jacques, cujas composições implicam fontes mantélicas mais enriquecidas. Isto, aliado ao expressivo volume de rochas vulcânicas intermediárias, reforça as hipóteses genéticas que envolvam a diversidade e importância dos reservatórios mantélicos, tornando, assim, os modelos de reciclagem de segmentos infracrustais no manto (processos de delaminação) mais atrativos.

Polaridade do magmatismo no final do Ciclo Brasiliano Os granitos estudados possuem teor moderado a alto de álcalis $(8 \%$ a $10 \%)$, e as diferenças indicativas da alcalinidade estão traduzidas mais pelas variações no conteúdo de $\mathrm{CaO}$ e $\mathrm{Al}_{2} \mathrm{O}_{3}$, refletidas na razão cálcico-alcalina, índice agpaítico e, em parte, na composição dos anfibólios. Genericamente, pode-se dizer que no oeste ocorrem os granitos metaluminosos e alcalinos (Suíte Intrusiva Saibro), do tipo A (Collins et al. 1982), enquanto no leste, predominam os tipos cálcico-alcalinos altamente fracionados (Suíte Granítica Dom Feliciano), também considerados do tipo A (Sylvester 1989, Whalen et al. 1987). Particularmente no Escudo Sulriograndense, no entanto, é possível separá-los em grupos distintos, com base em critérios de campo, geoquímicos e isotópicos. Estas variações composicionais regionais foram apontadas inicialmente por Jost et al. (1984) e indicam maior influência da subducção na gênese dos granitos do leste, que nos do oeste. Os principais contrastes no conteúdo de elementos traço incompatíveis, sugestivos de diferenças nos processos geradores ou nas fontes, é bem ilustrado pela razão $\mathrm{Y} / \mathrm{Nb}$ e pelo conteúdo de $\mathrm{Nb}, \mathrm{Rb}$ e $\mathrm{K}_{2} \mathrm{O}$ (Figs. 2 e 3 ). $\mathrm{Na}$ porção leste, as associações graníticas são mais homogéneas e pos-

Suem valores de $\varepsilon_{\text {Nd }}$ negativo e altas razões $\left({ }^{87} \mathrm{Sr} /{ }^{86} \mathrm{Sr}\right) \mathrm{i}$ ${ }^{206} \mathrm{~Pb} /{ }^{204} \mathrm{~Pb},{ }^{207} \mathrm{~Pb} /{ }^{204} \mathrm{~Pb}$ (Figs. 10B e $13 \mathrm{~A}$ ). Tais feições indicam derivação a partir de fontes enriquecidas em $\mathrm{Rb}, \mathrm{U}$ e Th, similares às de ambientes orogênicos proximais (Zartman \& Haines 1988), que também podem ser entendidas como devidas à proximidade aofront colisional. Mesmo os tipos de afinidade alcalina marcante, como o Complexo Granítico Encruzilhada do Sul c Maciço Sicnítico Piquiri, guardam algumas destas feições geoquímicas c isotópicas regionais (Fig. 13) (Gastai et al. 1995b).

A diversidade composicional das associações graníticas e de rochas intermediárias a básicas correlatas, relacionadas aos eventos finais do Ciclo Brasiliano (540 - $610 \mathrm{Ma}$ ) no setor oeste, é típica de ambientes mais afastados dofront colisional. As idades isotópicas dos granitos com filiações diversas, cálcico-alcalinos alto $\mathrm{K}$, shoshoníticos e alcalinos (Tabela 1), evidenciam a proximidade temporal entre episódios magmáticos distintos. A natureza dos reservatórios fontes envolvidos,
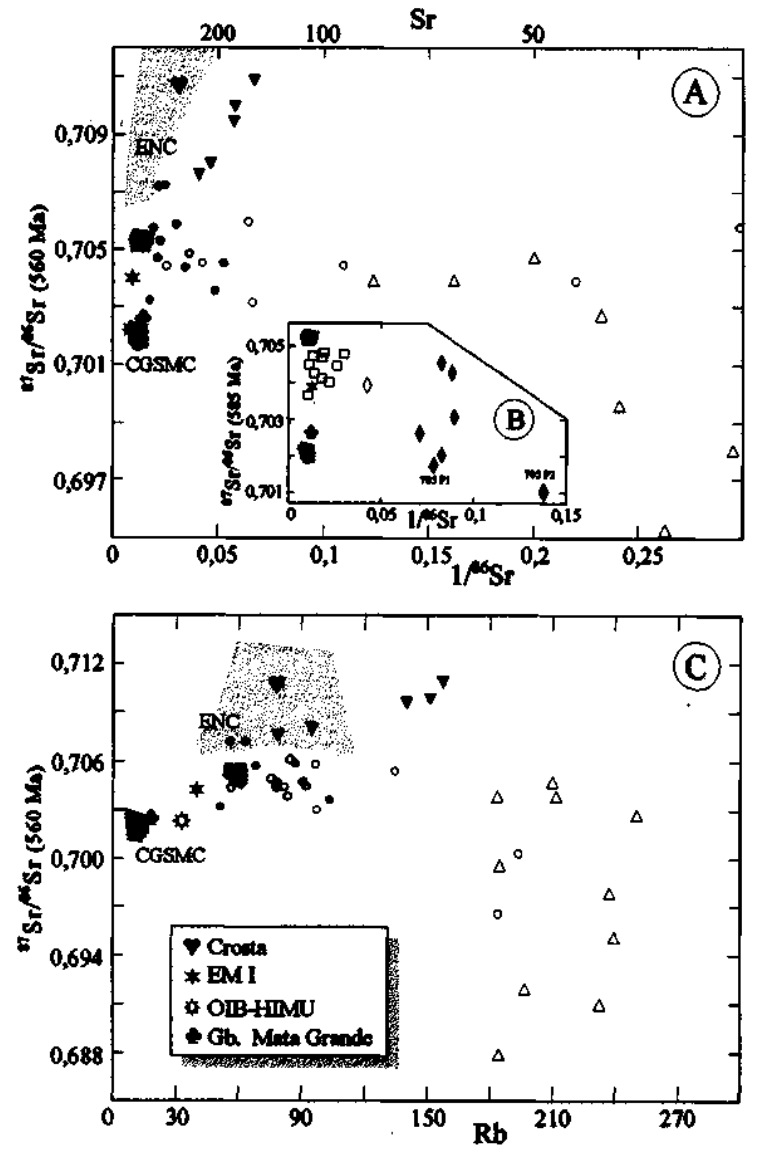

Figura 12 - Variações na razão ${ }^{87} \mathrm{Sr}{ }^{86} \mathrm{Sr}(t)$ versus $1{ }^{86} \mathrm{Sr}$ ( $\boldsymbol{A}$ e $\boldsymbol{B})$, e $R b-(\boldsymbol{C})$, de alguns granitóides da porção oeste com diferentes filiações, considerando as idades médias para cada grupo (vide Tabela 1): $(\boldsymbol{A} \boldsymbol{e} \boldsymbol{C})-560 \mathrm{Ma}: C G S S \boldsymbol{\nabla} \mathrm{T}$. monzogranitos do núcleo e $\mathrm{A}$-sienogranitos periféricos) $e$ CGCS (•-granodioritos; cinza - monzogranitos e o -leucogranitos); e (B) - $585 \mathrm{Ma}$ : fácies graniticas do CILS. Símbolos e referências, como na figura 2 e Tabela J. Em (B), são identificadas duas amostras do pertita granito situadas na porção sul do complexo (Fig. 5) (ponto 715 extrapola o diagrama). São também exibidos os campos de algumas associações regionais (dados de Soliani 1986): CGSMC (cinza escuro) - Complexo Granulítico Santa Maria Chico, considerado como equivalente à crosta inferior; ENC (cinza claro) - Gnaisse Encantadas, de idade paleoproterozóica; a composição de um amostra do Gabro Mata Grande, interpretado como representativo do manto não enriquecido em elementos incompativeis; e a média de reservatórios fontes clássicos (Weaver 1991; Hofman 1988; Wedepohl 1996). Figure 12 - Variation of ${ }^{87} \mathrm{Sr} /{ }^{86} \mathrm{Sr}(\mathrm{t})$ versus $1 /{ }^{86} \mathrm{Sr}$ - (A and B), and $\mathrm{Rb}$ - (C), for some granitoids from the west sector with different genetic signatures, taking the averages ages for each group (see Table 1): (A and C) - $560 \mathrm{Ma}$ : CGSS ( $\boldsymbol{\nabla}$ - nucleus monzogranites, and A - peripherical syenogranites), and CGCS ( - granodiorites; gray - monzogranites, and $\circ$ - leucogranites); and (B) - 585 Ma: CILS granitic fácies. Symbols and references as in figure 2 and Table 1. The two sarnples of the pcrtithe granite situated in the south portion of the complex (Fig. 5) are identified in B (the 715 ones plots out of the diagram). The field of some regional associations are also shown (data after Soliani 1986): CGSMC (dark gray) - Santa Maria Chico Granulitic Complex, taking as equivalent to the lower crust; ENC (light gray) - Encantadas Gneiss, with a paleoproterozoic age; the composition of one sample of the Mata Grande Gabbro, interpreted as representative of the non-enriched mantle; and the average of the common source reservoirs (Weaver 1991; Hofman 1988; Wedepohl 1996) 
manto ou crosta, é um dos fatores salientes na composição destas rochas, que permite estabelecer domínios regionais. Os dois tipos de granitos metaluminosos de afinidade alcalina pertencentes à Suíte Intrusiva Saibro seguem a tendência regional, havendo também a transição no tempo para tipos com envolvimento crustal sucessivamente maior. Desta forma, os magmas parentais dos granitos metaluminosos s.s. (Granito Jaguari e Complexo Granítico São Sepé) foram gerados em evento mais tardio (540-560 Ma) e com diversificada contribuição crustal, enquanto, nos metaluminosos fortemente alcalinos, a derivação mantélica é mais evidente e sua evolução está relacionada a episódio precoce (580-590 Ma), pelo menos, na região de Lavras do Sul (Tabela 1). Por outro lado, a natureza particular do Complexo Granítico Ramada sugere o envolvimento de fonte mantélica distinta dos demais, intensamente modificada em eventos prévios de subducção. A proximidade desse complexo à uma das principais ocorrências dos granitóides e gnaisses cálcico-alcalinos médio a baixo $\mathrm{K}$, formados durante evolução de arco magmático (700-750 Ma), fortalece esta ideia.

CONSIDERAÇÕES FINAIS As diferenças entre granitos composicionalmente similares das porções leste e oeste do escudo refletem posições geotectônicas distintas, como visualizado nos modelos existentes. Embora os três conjuntos de granitos metaluminosos, de afinidade ou tendência alcalina, possam ser englobados como tipo A, suas características geoquímicas e isotópicas revelam fontes ou processos geradores diversos. No setor leste, predominam os granitóides cálcico-alcalinos evoluídos (Batólito Pelotas), característicos de ambientes mais próximos ao/ro/tfcolisional, ou de regiões com maior espessamento crustal.

Na porção oeste, as associações magmáticas parcialmente cronocorrelatas às do leste exibem maior diversidade composicional, incluindo granitos cálcico-alcalinos alto $\mathrm{K}$ c rochas vulcânicas e plutônicas, de afinidade alcalina e shoshonítica. Além da contemporaneidade entre estes tipos composicionais, os dados isotópicos indicam que, especialmente o magmatismo alcalino (super)saturado, estende-se até 540-560 Ma, representando pelo menos dois episódios sucessivos. A polaridade do magmatismo tardio do Ciclo Brasiliano na porção oeste é para oeste-noroeste, e se traduz pela passagem das composições cálcico-alcalinas alto $\mathrm{K}$ para alcalinas e, entre essas, dos tipos metaluminosos para pcralcalinos. Os episódios magmáticos cálcico -alcalino alto $\mathrm{K}$ e shoshonítico são contemporâneos à fase final do evento de trancorrência NE-SW, e a diferente intensidade dos efeitos dessa resultam da localização dos granitos, em zonas de alta c baixa deformação. Os episódios de afinidade alcalina (super)saturada são, em parte concomitantes aos mesmos, mas, em sua maioria, posicionam-se durante regime dominantemente extensional. Neste setor, é possível identificar domínios regionais transversais, controlados pela composição e tipo dos reservatórios fontes envolvidos.

1) granitóides e rochas intermediárias a básicas, com forte assinatura mantélica - situados no setor centro-leste (Lavras do Sul). Representam eventos precoces (580 - $610 \mathrm{Ma}$ ), cronocorrelatos ao final do magmatismo granítico da porção leste, com afinidade cálcico-alcalina altamente fracionada (595 Ma, Babisnki et al. 1996). Os dados geoquímicos e isotópicos, embora preliminares, sugerem o envolvimento de manto litosférico enriquecido na gênese destas rochas e cuja modificação ocorreu em eventos pretéritos (paleoproterozóicos), seja pela interação manto-crosta ou peja influência da subducção. Exibem baixas razões $\left({ }^{87} \mathrm{Sr} /{ }^{80} \mathrm{Sr}\right) \mathrm{i}(0,704-0,705)$ e baixos valores negativos de $\mathrm{ENd}$, próximos à composição do manto primitivo. Incluem composições shoshoníticas e os tipos metaluminosos fortemente alcalinos da Suíte Intrusiva Saibro (fácies alcalinas do Complexo Intrusivo Lavras do Sul e,

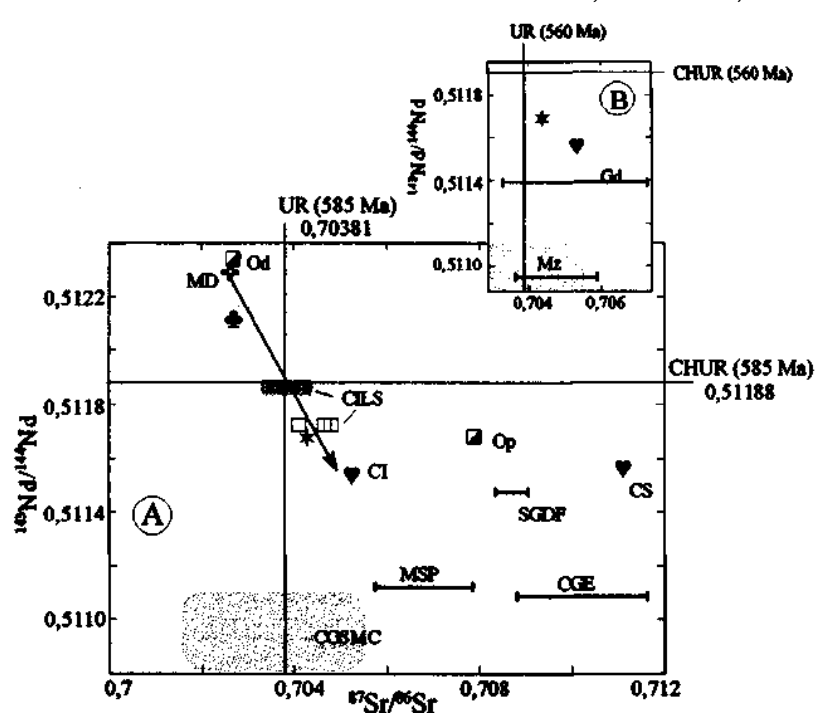

Figura 1, - Diagrama de correlação isotópica $\mathrm{Sr} / \mathrm{Sr}(t)$ versas ${ }^{143} \mathrm{Nd} /{ }^{144} \mathrm{Nd}(t)$ das fácies granitíticas do CILS - (A), e CGCS -(B), separados em função da idade, como na figura 12 (dados de Babinski et al 1995; 1996; Hartmann 1987; Mantovani et al. 1987). Em (A), estas composições são comparadas a exemplos de granitos da porção leste (cálcico-alcalino altamente/racionado - SGDF; e tipos mais alcalinos: MSP - Maciço Sienítico Piqniri e CGE - Complexo Granítico Encruzilhada do Sul), além dos principais reservatórios mostrados nas figuras 10 e 12. Seta indica sentido do enriquecimento do manto (vide texto). CILS: D - monzogranitos do núcleo do complexo (ponto 712, Fig. 5), e campo cinza -fácies alcalinas da porção sul do complexo (pontos 705 e 715, Fig. 5), considerando a razão ${ }^{87} \mathrm{Sr}{ }^{86} \mathrm{Sr}$ (t) média desta fácies, em face dos distúrbios no sistema isotópico $\mathrm{Rb}-\mathrm{Sr}$ nas amostras deste local (vide Fig. 12).

Figure $13-{ }^{87} \mathrm{Sr} /{ }^{86} \mathrm{Sr}(\mathrm{t})$ versus ${ }^{143} \mathrm{Nd} /{ }^{44} \mathrm{Nd}(\mathrm{t})$ isotope correlation diagram for thc CILS alkalinc fácies - (A), and CGCS - (B), separated on the age basis, as in figure 12 (data aftcr Babinski et al. 1995; 1996; Hartmann 1987; Mantovani et al. 1987). In (A), these compositions are compared with granitic examples from the east portion (highly evolved calc-alkaline - SGDF; and alkaline types: MSP - Piquiri Syenitic Massive; and CGE - Encruzilhada do Sul Granitic Complex), and with the main source reservoirs shown in the figures 10 and 12. Arrow highlights the sense of the mantle enrichment (see text for dctails). For the CILS: D - nucleus monzogranites (point 712, Fig. 5), and gray field - alkaline fácies from the south portion of the complex (points 705 and 715 , Fig. 5), taking the average ${ }^{87} \mathrm{Sr}{ }^{86} \mathrm{Sr}(\mathrm{t})$ ratio for this fácies, due to the disturbances in the $\mathrm{Rb}-\mathrm{Sr}$ isotopic system in the samples of this área (secFig. 12).

talvez, Quartzo Monzonito Tuna). Esses últimos ocorrem normalmente em pequenos corpos intrusivos ou porções associados aos granitóides menos evoluídos, shoshoníticos e cálcico-alcalinos alto K. A transição entre os dois eventos magmáticos, com afinidade geoquímica diversa, pode ser relacionada a heterogeneidades em pequena escala nas fontes mantélicas, ou na interação manto-crosta, cujas diferenças iniciais dos magmas parentais foram posteriormente ampliadas durante a diferenciação magmática (Gastai \& Nardi 1997).

2) granitos com contribuição crustal importante - a nortenordeste (Caçapava do Sul - São Sepé). Suas características composicionais sugerem a existência de crosta mais antiga, paleoproterozóica e heterogénea neste setor. Representam um possível evento magmático relativamente mais jovem (540$560 \mathrm{Ma}$ ), e incluem composições cálcico-alcalinas alto $\mathrm{K}$ e os tipos metaluminosos S.S. da Suíte Intrusiva Saibro. Caracterizam-se por altos valores negativos de eNd (-10 e -20), mo- 
derados a baixos da razão $\left({ }^{87} \mathrm{Sr} /{ }^{86} \mathrm{Sr}\right)$ i e, no caso dos alcalinos, baixas razões isotópicas do $\mathrm{Pb}$. As variações composicionais entre eles traduzem a participação, em sua gênese, de segmentos crustais diversos e misturados em diferentes proporções. $\mathrm{Na}$ região dos granitos Jaguari-Lavras do Sul (Fig. 5), a sucessão no tempo entre os diversos eventos magmáticos tardios do Ciclo Brasiliano está bem caracterizada: shoshonítico - 590-600Ma; metaluminoso fortemente alcalino - $580 \mathrm{Ma}$; e metaluminoso s.s., de afinidade alcalina -540560Ma. Esta transição pode ser atribuída à evolução de eventos magmáticos num período de tempo relativamente grande (30-40 Ma), favorecendo o sucessivo crescimento da contribuição crustal como discutem Huppert \& Sparks (1988). Na passagem das composições shoshoniticas para os termos precoces de afinidade alcalina (metaluminosos fortemente alcalinos), dominam os efeitos decorrentes de variações nas fontes mantélicas. Estes registros são mais proeminentes entre as rochas shoshoníticas, o que é ilustrado pela diversidade composicional dos termos básicos a intermediários. Posteriormente, a evolução entre as composições graníticas metalumi- nosas e alcalinas da Suíte Intrusiva Saibro está mais relacionada ao aumento da contribuição crustal, em magmas parentais mantélicos derivados de fontes similares.

Agradecimentos Ao Prof. Dr. Lauro V. S. Nardi (IG/UFRGS) pela discussão produtiva e engrandecedora ao desenvolvimento das ideias expostas. Em diferentes etapas, este trabalho contou com a colaboração das colegas, enquanto bolsistas de iniciação científica, Mônica M. da Fonseca e Lúcia S. Orliz. A elaboração do mapa geológico da região de Lavras do Sul, (fig. 5), foi efetuada em conjunto com os colegas Prof. Dr. Evandro F. de Lima e Profa. Msc. Djanira L. Saldanha (IG/UFRGS). A Profa. Tamar M. B. Galembeck do Laboratório de Estudos de Zircão (Instituto de Geociências e Ciências Exatas, UNESP), pelo apoio na separação e obtenção dos concentrados de zircão. O suporte financeiro para o desenvolvimento deste trabalho foi fornecido pêlos seguintes projetos: $\mathrm{CNPq} \mathrm{n}^{\circ} 40$ 2494/90-3 e 52 1302/93-5; FAPERGS n ${ }^{\circ}$ 94/0344-0 e FINEP/PADCT n ${ }^{\circ} 65910362.00$.

\section{REFERENCIAS}

Ague, J.J. \& Brimhall, G.H. 1988. Regional variations in bulk chemistry, mineralogy, and the compositions of mafic and accessory minerais in the batholiths of Califórnia. Geolgical Society of America Bulletin., 100(6): 891-911.

Anderson, J.L. \& Smith, D.R. 1995. The effects of temperature and $\mathrm{fO}_{2}$ on the Al-in-hornblende barometer. American Mineralogist., 80:549-559.

Babinski, M. Chemale Jr., F.; Hartmann, L.A.; Van Schmus, W.R. \& Silva, L.C. da 1996. Juvenile accretion at 750-700 Ma in Southern Brazil. Geologv, 24(5): 439-442

Babinski, M. Chemale Jr., F.; Hartmann, L.A.; Van Schmus, W.R. \& Silva, L.C. da 1995. Acresção juvenil no Bloco São Gabriel e retrabalhamento crustal no Cinturão Dom Feliciano durante o Ciclo Brasiliano: evidências isotópicas. In: SIMPÓSIO SUL-BRASILEIRO DE GEOLOGIA, 6, Porto Alegre, Anais..., SBG (resumos expandidos), p. 105-107.

Baker, B.H. 1987. Outline of the petrology of the Kenyan rift alkaline province. In: Fitton, J. G. \& Upton, B.GJ. (Eds.). Alkaline Igneous Rocks. Geological Society Pubication, 30: 293-312.

Barros, C.E. \& Nardi, L.V.S. 1994. O Maciço Granítico Santo António, RS: Magmatismo Neoproterozóico de Afinidade Shoshonítica. Anais da Academia Brasileira de Ciências, 66(4): 441-465.

Brown,. G.C. 1982. Calc-alkaline intrusive rocks: their diversity, evolution, and relation to volcanic ares. In: Thorpe, R.S. (Ed.). Andesites: Omgenic Andesites and related rocks. London, John Wiley, p. 437-461.

Caroff, M.; Maury, R.C.; Leterrier, J.; Joron, J.L.; Cotten, J. \& Guille, G. 1993. Trace element behavior in the alkali basalt-comenditic trachyte series from Mururoa Atoll, French Polynesia. Litlws, 30(1): 1-22.

Chemale Jr., F.; Hartmann, L.A. \& Silva, L.C. da, 1995. Stratigraphy and Tectonism of Brasiliano Cycle in Southern Brazil. Proccedings Volume Proterozoic Crust (in press)

Collins, W.J.; Beams, S.D.; White, A.J.R. \& Chappell, B.W. 1982. Nature and origin of A-type granites with particular reference to Soulheasthern Austrália. Contribution to Mineralogy and Petrology, 80(2): 189-200.

Czamanske, G.K. \& Wones, D.R. 1973. Oxidation during magmatic differentiation, Finmark Complex, Oslo Área, Norway. Part 2, the mafic silicates. Journal of Petrology, 13: 493-509.

Czamanske, G.K.; Wones, D.R. \& Eichelberger, J.C. 1977. Mineralogy and petrology of the intrusive complex of the Pliny Range, New Hampshire. American Journal of Science, 277(9): 1073-1123.

Czamanske, G.K.; Ishihara, S. \& Atkin, S.A. 1981. Chemistry of rock-forming minerais of the Cretaceous-Paleocene Batholith in Southwestern Japan and implications for magma génesis. Journal of Geoph $\mid$ sical Research, 86(B.11): 10431-10469.

Doe, B.R. \& Zartman, R.E. 1979. Plumbotectonics I, The Phanerozoic. In: B ARNÊS, H. L. (Ed.). Geochemistry ofHydrothermal Ore Deposiís, 2' ed., Wiley Interscience, p. 22-70.

Eby, G.N. 1990. The A-type granitoids: A review of their occurrence and chemical characteristics and speculations on their petrogenesis. Li t lios. 26(1/2): 115-134.

Ewart, A. 1982. The mineralogy and petrology of Tertiary-recent orogenic volcanic rocks: with special reference of the andesite-basaltic compositional range. In: THORPE, R.S. (Ed.). Andesites: Orogenic Andesites and related rocks. London, John Wiley, p. 25-95.

Fernandes, L.A.D.; Tommasi, A. \& Porcher, C.C.; Koester, E.; Kraemer, G. Scherer, C.M.S. \& Menegat, R. 1992. Granitóides brasilianos precoces do Cinturão Dom Feliciano. Caracterização geoquímica e discussão estratigráfica. Pesquisas, 19(2): 195-215.
Frantz, J.C. \& Nardi, L.V.S. 1992. Litogeoquímica e evolução de granitóides cálcico-alcalinos da região leste do Escudo Sul-riograndense. Pesquisas, 19(1): 13-25.

Gastai, M.C.P. 1997. Suite Intrsiva Saibro, RS: Avaliação de um Modelo Petrológico. Porto Alege, 365p. (Tese de Doutorado, Universidade Federal do Rio Grande do Sul).

Gastai, M.C.P. \& Nardi, L.V.S. 1992. Petrogênese e evolução do Granito Jaguari: um típico representante metaluminoso da Suíte Intrusiva Alcalina Saibro, RS. Geochimica Brasiliensis, 6(2): 169-189.

Gastai, M.C.P. \& Nardi, L.V.S. 1997. The alkaline and shoshonitic intrusives in the region of the Taquarembó Plateau, Southern Brazil: Are they genetically related? In: International symposium on Granites and Associated

Mineralizations, 2, Salvador, Extended Abstracts and Program..., p.

$118-120$.

Gastai, M.C.P. \& Ortiz, L.S. 1997. Estudo dos feldspatos alcalinos do Granito Jaguari e Complexo Granítico São Sepé, RS: implicações sobre os processos tardi a pós-magmáticos. Anais da Academia Brasileira de Ciências (no prelo).

Gastai, M.C.P.; Schmitt, R.S. \& Nardi, L.V.S. 1992. Granitóides da parte centro/sudoeste do Escudo Sul-rio-grandense. Novos dados e discussão sobre a gênese e tipologia do magmatismo alcalino. Pesquisas, 19(2): $174-182$.

Gastai, M.C.P. Nardi, L.V.S \& Lafon, J.M. 1995a. Classificação dos granitóides pertencentes à Suíte Intrusiva Saibro (SIS), RS. In: Simpósio Sul-brasileiro de Geologia, 6, Porto Alegre, boletim..., SBG. (resumos expandidos) p.72-76.

Gastai, M.C.P.; Vasquez, M.; Gotardo, E; Nardi, L.V.S. \&\& Bitencourt, M.F. 1995b. Diversidade composicional entre granitos metaluminosos de afinidade alcalina: exemplos do Escudo Sul-riograndense. In: Simpósio Sul-brasileiro de Geologia, 6, Porto Alegre, boletim ..., SBG. (resumos expandidos) p.63-66.

Gastai, M.C.P.; Sommer, C.A.; Lafon, J.M. \& Barros, C.E. 1997. Neoproterozoic alkaline (over)saturated volcanic-plutonic association of the Taquarembó Plateau, Southern Brazil: petrlogical evolution and genetic link with the shoshonitic magmatism. Precamhrian Research (no prelo).

Gaudette, H.E.; Lafon, J.M.; Moura, C.A.V. \& Scheller, T. 1993. Datação de monocristais de zircão por evaporação de $\mathrm{Pb}$, no Laboratório de Geologia isotópica da UFPA: Metodologia e primeiros resultados. In: Congresso Brasileiro de Geologia, 4, Brasília, Anais ..., SBGQ. (resumos expandidos) p. 236-237.

Giret, A.; Bonin, B. \& Leger, J.M. 1980. Amphibole compositional trends in oversaturated and undersaturated alkaline plutonic ring-complexes. Canadian Mineralogist., 18(4): 481-495.

Gomes, M.E.B.; Almeida, D. P. M de; Philipp, R.P. \& Pintaúde, D. 1991. Caracterização mineralógica e geoquímica do Cerro Sandí, Piratini, RS. Acta Geologia Leopoldensia 34: 123-144

Harris, C. 1983. The petrology of lavas and associated plutonic inclusions of Ascension Island. Journal of Petrology, 24:424-470.

Hartmann, L.A. 1987. Isócrona Sm-Nd de 2,1 Ga em minerais de duas amostras do Complexo Granulítico Santa Maria Chico, RS. In: Simpósio Sul-brasileiro de Geoquímica, 1, Porto Alegre, Anais .... SBGQ. v. 1: $105-111$.

Hofmann, A.W. 1988. Chemical differentiation of the Earth: the relationship between mantle, continental crust, and oceanic crust. Earth Planetary Science Letters, 90(3): 297-314.

Hradetzky, H. \& Lippolt, H.J. 1993. Generation and distortionof Rb/Sr whole-rock isochrons-effects of metamorphism and alteration. European Journal of Mineralogy, 5(6): 1175-1193. 
Huppert, H.E. \& Sparks, R.S. 1988. The generation of granitic magmas by intrusion of basalt into continental crust. Journal of Petrology, 29:599-624.

Jost, H.; Frantz, J.C. \& Wernick, E. 1984. Implicações geotectônicas da variação composicional, temporal e regional dos granitóides do Ciclo Brasiliano no Escudo Sul-riograndense. In: Simpósio Sul-brasileiro de Geologia, 33, Rio de Janeiro, Anais..., SBG, v. 6, p. 2978-3000.

Kober, B. 1986. Whole-grain evaporation for ${ }^{207} \mathrm{~Pb} /{ }^{206} \mathrm{~T}^{`} \mathrm{~b}$-age-investigations on single zircons using a double-filament lhermal ion source. Contribution to Mineralogy and Petrology, 93: 482-490. Kober, B. 1987. Single-zircon evaporation combined with $\mathrm{Pb}^{+}$emitter bedding for ${ }^{207} \mathrm{~Pb} /{ }^{206} \mathrm{~Pb}$-age investigations using thermal ion mass spetrometry, and implications to zirconology. Contribution to Mineralogy and Petrology, 96: 63-71.

Lafon, J.M.; Rodrigues, E.M.; Scheller, T. 1993. Geocronologia Pb-Pb em feldspato e rocha total: Procedimento experimental e exemplos de aplicação. In: Simpósio Sul-brasileiro de Geoquímica, 4, Brasília, Anais ..., SBGQ. (resumos expandidos) p. 242-244.

Lalonde, A.E. \& Martin, R.F. 1983. The Baie-des-Moutons Syenitic Complex, La Tabatiere, Québec: II. The ferromagnesian minerais. Canadian Mineralogist $21: 81-91$

Leite, J.A.D. 1995. Datação SHRIMP U/Pb em zircões e o exemplo de dois corpos graníticos contrastantes no Escudo Sul-riograndense. In: Simpósio Sul-brasileiro de Geologia, 6, Porto Alegre, Boletim, SBG. (resumos expandidos) p. 5-12.

Lima, E.F. de \& Nardi, L.V.S. 1992. O magmatismo shoshonítico do Estado do Rio Grande do Sul. Uma revisão. Pesquisas, 19:190-194.

Lima, E.F. de \& Nardi, L.V.S. 1997. The Lavras do Sul Shoshonitic Association, southernmost Brazil: implications for the origin and evolution of shoshonitic magmatisrn. Submetido ao Journal of South America Earth Science.

Macambira, M.J.B.; Moura, C.A.V.; Lafon, J.M.; Scheller, T. \& Gaudette, H.E 1994. O método $\mathrm{Pb}$-Pb por evaporação em zircão: Avaliação dos dados obtidos no Laboratório de Geologia Isotópica da UFPA. In: Simpósio Sul-brasileiro de Geologia, 38, Camboriú, Anais .... SBG. (resumos expandidos) v. 2 p. 404-406.

MacDonald, R. 1994. Petrological evidence regarding the evolution of the Kenya Rift Valley. Tectonophysics, 236:373-390.

Manhes, G. 1982. Développement de Lénsemble Chronométrique U-Tli-Pb. Contribution à Ia Chronologie Initiale du Système Solaire. Paris, 294p. (Thèse de doctorat d'état, Université de Paris VII).

Manhes, G.; Minster, J.F. \& Allègre, C.J. 1978. Comparative uranium-thorium-lead and rubidium-strontium study of the Saint Sèverin amphoterite: consequences for early solar system chronology . Eartli Planetary Science Letters, 39:4-24.

Mantovani, M.S.M.; Hawkesworth, C.J. \& Basei, M.A.S. 1987. Nd and Pb isotope studies bearing on the crustal evolution of Southeastern Brazil. Revista Brasileira de Geoiências, 17:263-268

McCulloch, M.T.; Jaques, A.L.; Nelson, D.R. \& Lewis, J.D. 1983. Nd and Sr

isotopes in Kimberlites and lamrpoites from western Austrália: an enriched mantle origin. Nature, 302:400-403.

McKenzies, D. \& O'Nions, R. K. 1995. The source regions of Ocean Island basalts. Journal of Petrologv, 36( 1): 133-159.

Moura, C.A.V.; Gaudette, H.E.; Macambira, M.J.B.; Lafon, J.M. \& Scheller, T. 1996. Datação de monocristais de zircão por evaporação de $\mathrm{Pb}$ em filamento simples: comparação com resultados U-Pb. In: Simpósio Sul-brasileiro de Geologia, 39, Salvador, Anais ..., SBG. (resumos expandidos) v. 6 p.480-483.

Naime, R. \& Nardi, L.V.S. 1991. O Granito Ramada, porção oeste do Escudo Sul-riograndense: geologia, petrologia e geoquímica. Revista Brasileira de Geociências, 21:266-274.

Nardi, L.V.S. 1984. Geochemistry and Petrology ofthe Lavras Granile Complex,

RS, Brazil. London, 268p. (Doctor of Philosophy Thesis, Department of

Geology King's College, University of London)

Nardi, L.V.S. 1991. Caracterização petrográfica e geoquímica dos granitos metaluminosos da associação alcalina: revisão. Pesquisas, 18:44-57.

Nardi, L.V.S. \& Bitencourt, M.F. 1989. Geologia, petrologia e geoquímica do

Complexo Graníticode Caçapava do Sul. Revista Brasileira de Gtwiências,

19:153-169.

Nardi, L.V.S. \& Bonin, B. 1991. Post-orogenic and non-orogenic alkaline granite associations: The Saibro Intrusive Suite, Southern Brazil. A case study. Chemical Geology, 92:197-211.

Nardi, L.V.S.; Lima, E.F. de \& Gastai, M.C.P. 1992. Magmatismo no grupo Bom Jardim: afinidade geoquímica e significado geotectônico. In: Workshop sobre Bacias Molássicas Brasilianas, 1, São Leopoldo, Actas..., UN1SINOS. P. 82-89.

Novak, S. W. \& Mahood, G.A. 1986. Rise and fali of a basalt-lrachyte-rhyolite magma system atthe Kane Springs Wash Caldera, Nevada. Contribution to Mineralogy and Petrology, 94: 352-373.

Paim, P.S.G.; Lopes, R.C. \& Chemale Jr., F. 1995. Aloestratigrafia, sistemas deposicionais e evolução paleogeográfica da Bacia do Camaquã - Vcndiano superior/Ordoviciano inferior do RS. In: Simpósio Sul-brasileiro de Geologia, 6, Porto Alegre, Boletim..., SBG. (resumos expandidos) p. 39-50. Patterson, C. \& Tatsumoto, M. 1964. The significance of lead isotopes in detrital feldspar with respect to chemical differentiation within the Earth's mantle. Geochimiclia and Cosniochimica Acta, 28: 1-22.

Pearce, J.A.; Harris, N.B.W. \& Tindle, A.G. 1984. Trace element diagrams for the tectonic interpretation of granitic rocks. Journal of Petrology, 25:956-983.
Philipp, R.P. 1991. Geologia dos granitóides da região de Monte Bonito, Pelotas - RS: uma contribuição ao reconhecimento estratigráfico do setor oriental do escudo. Acta Geológica Leopoldensia, 33:71-128.

Remus, M.V.D.; McNaughton, N.J.; Hartmann, L.A. \& Fletcher, I.R. 1997a Zircon SHRIMP U/Pb and Nd isotope data of granitoids ofthe São Gabriel Block, southern Brazil: evidence for an Archaean/paleoproterozoic basement. In: International Symposium on Granites and Associated Mineralizsations, 2, Salvador, Extended abstracts and Program..., p. 271-272.

Remus, M.V.D.; McNaughton, N.J.; Hartmann, L.A.; Groves, D.I. \& Reischl, J.L. $1997 \mathrm{~b} . \mathrm{Pb}$ and $\mathrm{S}$ isotope signature of sulphides and constraints on timing and sources of $\mathrm{Cu}(\mathrm{Au})$ mineralisation at the Camaquã and Santa Maria Mines, Caçapava do Sul, southern Brazil. In: Simpósio Sul-Americano de Geologia Isotópica, 1, Campos do Jordão. Extended Abstract..., p. 253-255.

Roisenberg, A.; Loss, E.L.; Altamirano, J.A.F. \& Ferreira, A.C. 1983. Aspectos petrológicos e Geoquímicos do vulcanismo Pré-Cmbriano-Eo-Paleozóico do R.G.S., com base em elementos maiores. In: Simpósio Sul-brasileiro de Geologia, 1, Porto Alegre, Atas..., SBG. P 273-285.

Rock, N.M.S. 1987. The nature and origin of lamprophyres: an overview. In: Fitton, J.G. \& Upton, B.G.J. (Eds.). Alkaline Igneous Rocks, Geological Society Publications, 30:191-226.

Sartori, P.L.P. 1978. Petrologia do Complexo Granítico São Sepé, RS. São Paulo, 195p. (Tese de Doutorado, Universidade de São Paulo).

Sartori, P.L.P. \& Kawashita, K. 1985. Petrologia e geocronologia do batólito granítico de Caçapava do Sul, RS. In: Simpósio Sul-brasileiro de Geologia, 2, Florianópolis, Anais..., SBG, p. 102-115.

Soliani Jr., E., 1986. Os dados Geocronológicos do Escudo Sul-rio-grandense e suas Implicações de Ordem Geotectônica. São Paulo, 340p. (Tese de Doutorado, Universidade de São Paulo)

Sommer, C.A. 1994. O Vulcanismo Ácido Alcalino da Porção Sul do Platô do Taquarembó, Dom Pedrito, RS. Porto Alegre, 149p. (Dissertação de Mestrado, Universidade federal do Rio Grande do Sul).

Stacey, J.S. \& Kracmers, J.D. 1975. Approximation of terrestrial lead isotope evolution by a two-stage inodel. Earth Planeary Science Letters, 26:207-221.

Sylvester, P.J. 1989. Post-collisional alkaline granites. Journal of Geology, 97:261-280.

Taylor, S.R. \& McLennan, S.M. 1985. The Continental Crust: Its Composition and Evolution. Oxford, Blackwell Scientific publications, 312p.

UFRGS 1992. Projeto Folhas Encruzilhada do Sul e Delfiiw, RS. Trabalho de Graduação, Curso de Geologia.

Vlack, S.R.F. \& Cordani, U.G. 1986. A sistemática Rb/Sr em rochas granitóides: considerações inteipretativas, limitações e exemplos brasileiros. Revista Brasileira de Geociências, 16:38-53.

Vieira Jr., N. \& Soliani Jr., E. 1989. Um novo modelo genético-evolutivo para o Maciço Granítico de Lavras do Sul, RS. Acta Geológica Leopoldensia, 29:143-160.

Watson, E. B. \& Hanïson, T. M. 1983. Zircon saturation revisited: temperature and composition effects in a variety of crustal magmas types. Earth and Planetary Science Letters, 64:295-304.

Weaver, B.L. 1991. The origin of ocean island basalt end-member compostions: trace element and isotopic constraints. Earth Planetary Science Letters, 104:381-397.

Wedepohl, K.H. 1995. The composition ofthe continental crust. Geochimica and Cosniochimica Acta, 59(7): 1217-1232.

Whalen, J.B.; Currie, K.L. \& Chappell, B.W. 1987. A-type granites: geochemical characteristics, discrimintaion and petrogenesis. Contribution to Mineralogy and Petrology, 95:407-419.

Wildner, W. \& Lima, E.F. de 1992. Considerações sobre os depósitos vulcanogênicos do grupo Bom Jardim nas regiões de Lavras do Sul e Cacapava do Sul, RS. In: Workshop sobre as Bacias Molássicas Brasilianas, 1, São Leopoldo, Atas..., UN1S1NOS. (resumos expandidos) p. 137-142.

Wildner, W.; Sander, A. \& Lopes, R.C. 1994. Estudo petrológico e litoquímico de uma parcela do vulcanismo ácido Eo-Paleozóico do Rio Grande do Sul -Formação Acampamento Velho. Pesquisas, 21:47-57.

Williamson. J.H. 1968. Least-squares fitting of a straight line. Canandiaii Journal ofPhysics, 46:18-45.

Wilson, M. 1989. Igneous Petrogenesis. Unwin Hyman Ltd., London, 466p.

York, D. 1966. Least-squares fitting of a straight line. Canadian Journal of P/n.v/c.v,44:1079-1086.

York, D. 1969. Least-squares fitting of a straight line with correlated errors. Earth Planetary Science Letters, 5: 320-324.

Zartman, R. E. \& Haines, S.M. 1988. The plumbotectonic model for Pb isotopic systematics among major terrestrial reservoirs - A case for bi-directional transport. Geochimica and Cosniochimica Acta, 52:1327-1339.

Zheng, Y.-F. 1989. Influences ofthe nature ofthe initial Rb-Sr system on isochron validity. Chemical Geology, 80:1-16.

Zindler, A. \& Hart, S. 1986. Chemical geodynamics. Animal Review Earth Planetary Science, 14

Manuscrito A-A922

Recebido em 28 de outubro de 1997 Revisão dos autores em 25 de fevereiro de 1998 Revisão aceita em 03 de março de 1998 